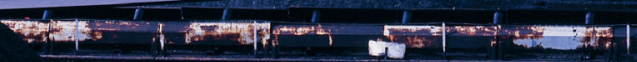

International

iea

Energy Agency

\title{
POWER GENERATION FROM COAL
}

Ongoing Developments and Outlook 



\title{
POWER GENERATION FROM COAL
}

\author{
Ongoing Developments and Outlook
}


The International Energy Agency (IEA), an autonomous agency, was established in November 1974. Its primary mandate was - and is - two-fold: to promote energy security amongst its member countries through collective response to physical disruptions in oil supply, and provide authoritative research and analysis on ways to ensure reliable, affordable and clean energy for its 28 member countries and beyond. The IEA carries out a comprehensive programme of energy co-operation among its member countries, each of which is obliged to hold oil stocks equivalent to 90 days of its net imports. The Agency's aims include the following objectives:

- Secure member countries' access to reliable and ample supplies of all forms of energy; in particular, through maintaining effective emergency response capabilities in case of oil supply disruptions.

- Promote sustainable energy policies that spur economic growth and environmental protection in a global context - particularly in terms of reducing greenhouse-gas emissions that contribute to climate change.

- Improve transparency of international markets through collection and analysis of energy data.

- Support global collaboration on energy technology to secure future energy supplies and mitigate their environmental impact, including through improved energy efficiency and development and deployment of low-carbon technologies.

Find solutions to global energy challenges through engagement and dialogue with non-member countries, industry, international organisations and other stakeholders.

IEA member countries:

(c) OECD/IEA, 2011

\section{International Energy Agency}

9 rue de la Fédération

75739 Paris Cedex 15, France

www.iea.org

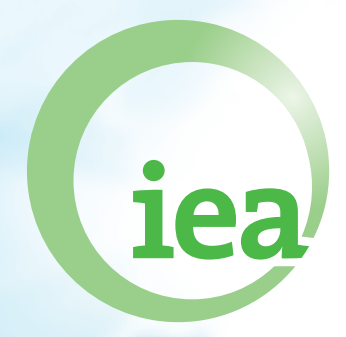

\section{International Energy Agency}

Slovak Republic

Spain

Sweden

Switzerland

Turkey

United Kingdom

United States

The European Commission

also participates in

the work of the IEA. 


\section{Table of Contents}

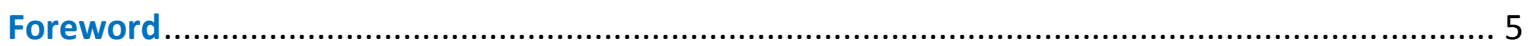

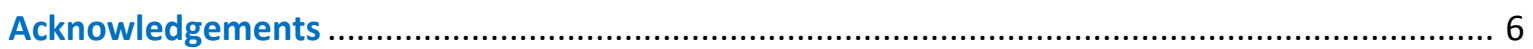

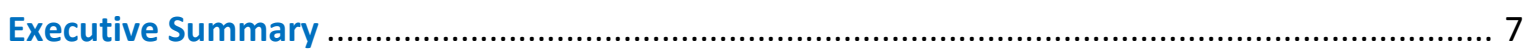

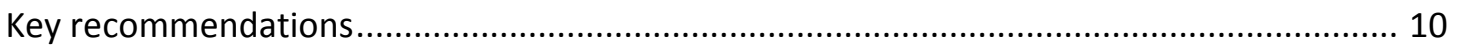

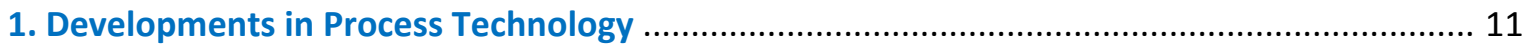

Supercritical and ultra-supercritical pulverised coal-fired technology .................................. 11

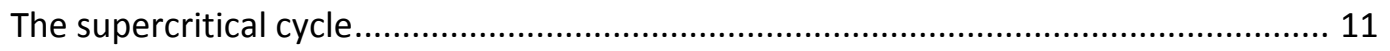

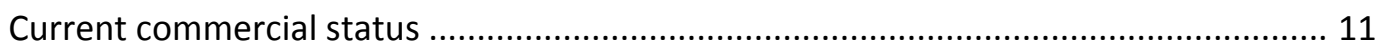

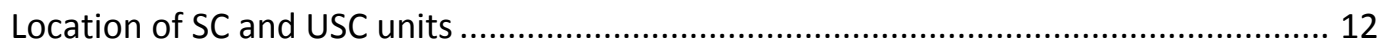

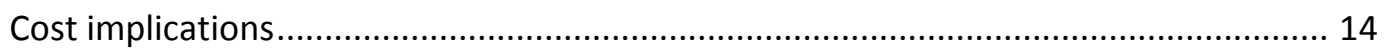

Barriers to widespread adoption of supercritical units ................................................... 14

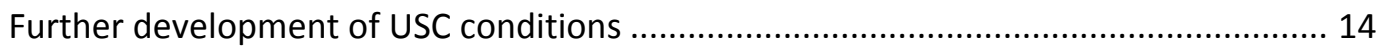

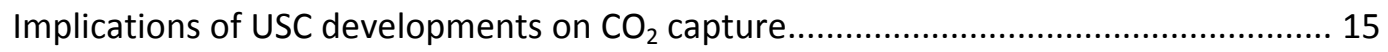

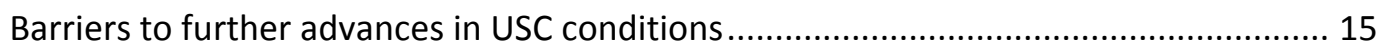

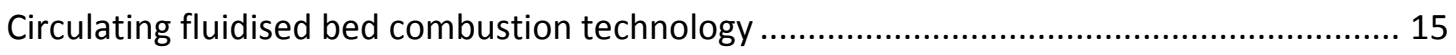

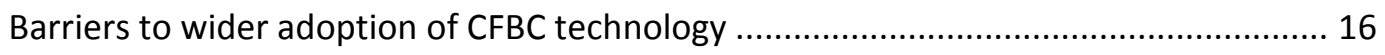

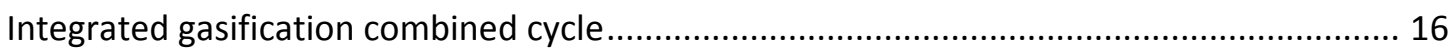

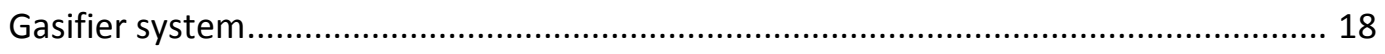

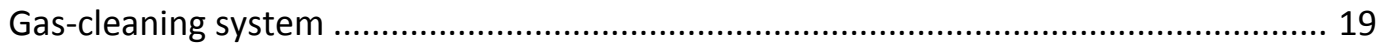

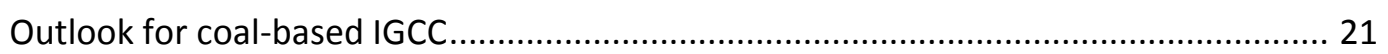

$\mathrm{CO}_{2}$ capture

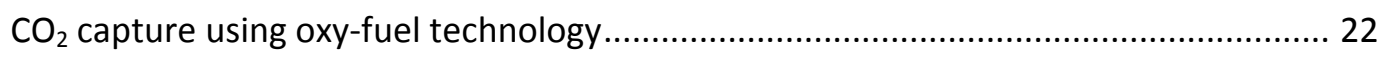

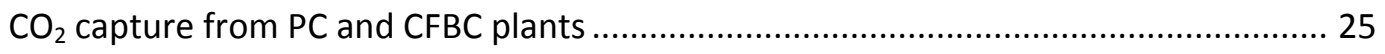

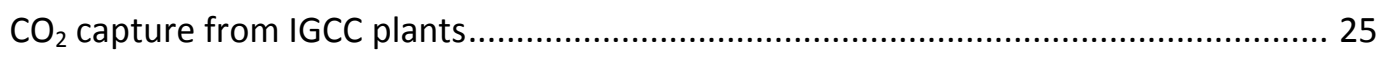

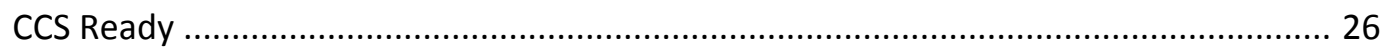

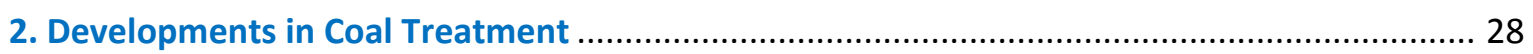

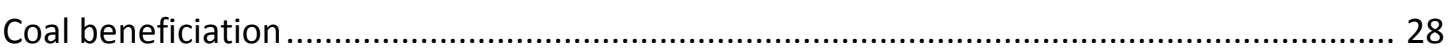

Need for pricing incentives for coal beneficiation......................................................... 29

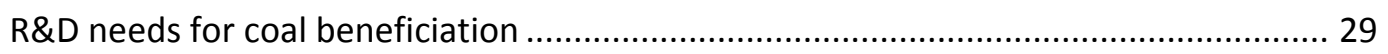

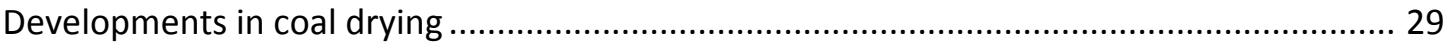

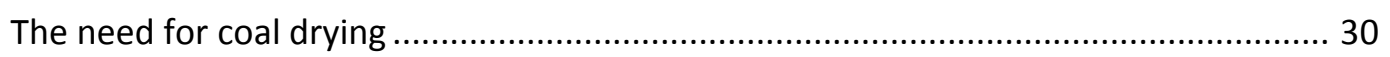

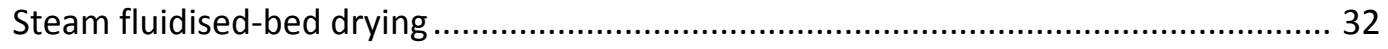

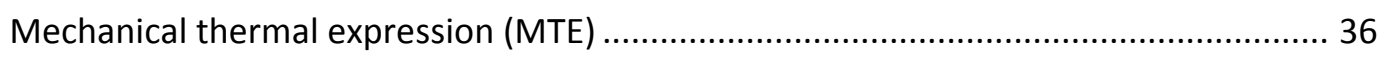

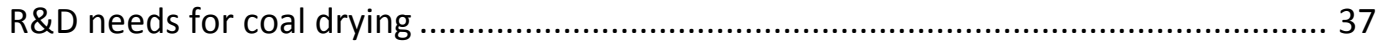




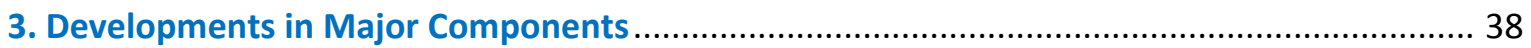

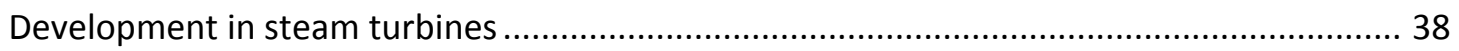

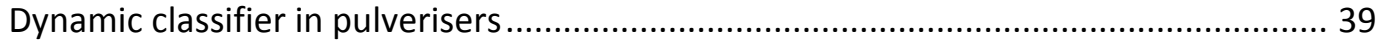

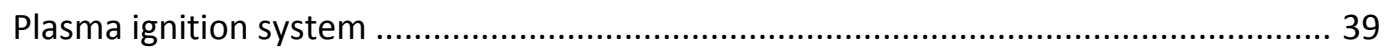

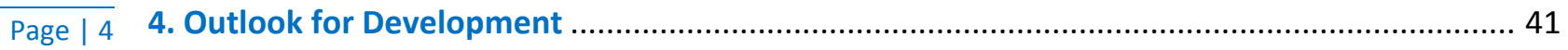

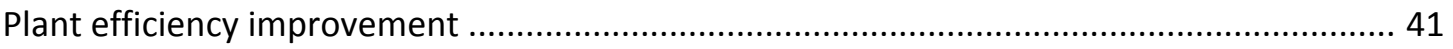

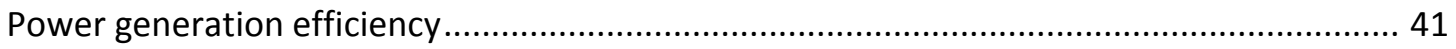

Outlook of ongoing developments in power generation ................................................... 42

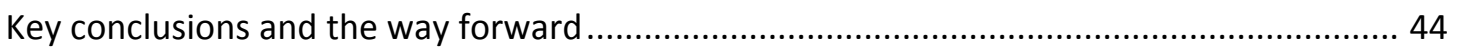

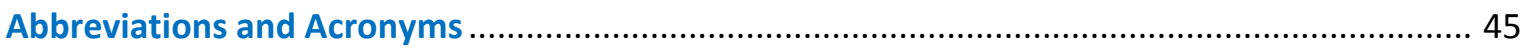

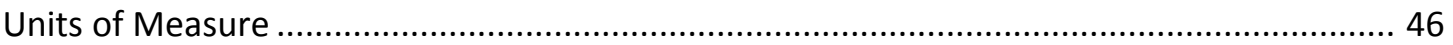

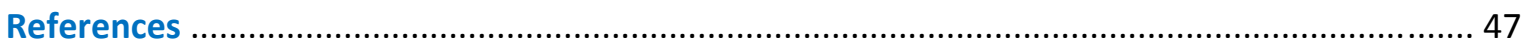

\section{List of Figures}

Figure 1 Location of advanced PCC plants and their share in coal-fired power generation............ 12

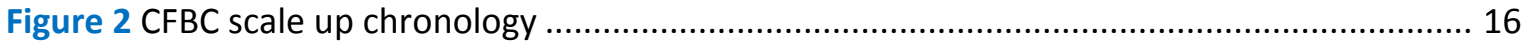

Figure 3 Major components of an IGCC system without $\mathrm{CO}_{2}$ capture........................................ 17

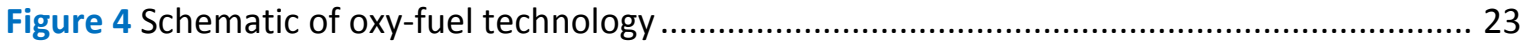

Figure 5 High-ash and/or high-moisture containing coals often termed as lignites ...................... 30

Figure 6 Illustration of boiler size variation with moisture content in coal .................................... 31

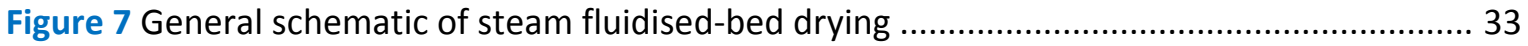

Figure 8 WTA lignite drying in comparison with conventional system ......................................... 34

Figure 9 WTA demonstration lignite drying plant on Niederaussem K ...................................... 34

Figure $10 \mathrm{~A}$ schematic of the lignite fuel enhancement system, which uses waste heat from condenser water and flue gas................................................................................... 35

Figure 11 Process flow diagram of the MTE Process - the press shown in horizontal orientation 36

Figure 12 Photograph of the dried product from the $15 \mathrm{t} / \mathrm{h}$ MTE Rig ......................................... 37

Figure 13 Trend of heat rate development through advanced turbine blade design ..................... 39

Figure 14 Efficiency improvement potential of hard coal-fired plants ......................................... 42

List of Tables

Table 1 Major supercritical units - recently commissioned, under construction or planned ........ 13

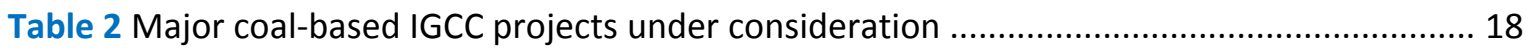

Table 3 Pilot and demonstration projects on oxy-fuel technology (with coal)................................ 24

Table 4 Impact of capture retrofit on IGCC plant design .................................................................. 26

Table 5 Summary of efficiency improvements that can be made in an existing plant................... 41

\section{List of Boxes}

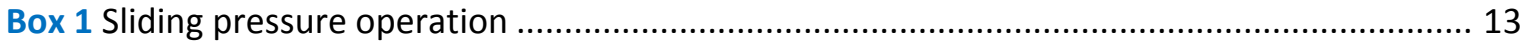

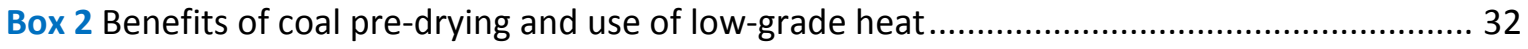

Box 3 Key developments in instrumentation and control ........................................................... 40 


\section{Foreword}

Coal is an important source of energy for the world, particularly for power generation. Demand for coal has grown rapidly over the last decade, outstripping that for gas, oil, nuclear and renewable energy sources. This comes at a cost. Coal contributes to over $40 \%$ of global anthropomorphic $\mathrm{CO}_{2}$ emissions and more than $70 \%$ of $\mathrm{CO}_{2}$ emissions that arise from power generation are attributed to coal. To play its role in a sustainable energy future, its environmental footprint needs to be reduced; using coal more efficiently is an important first step. Beyond efficiency improvement, carbon capture and storage (CCS) must be deployed to make deep cuts in $\mathrm{CO}_{2}$ emissions.

This report focuses mainly on developments to improve the performance of coal-based power generation technologies, which should be a priority - particularly if CCS takes longer to become established than currently projected. CCS is only touched upon in this report as several other IEA publications address this topic in much more detail. The intent has been to look closely at the major ongoing developments in process technology, plant equipment, instrumentation and control, considering their status and reflecting upon their potential.

Clean coal technologies are not as widely deployed as they should be. Improving steam conditions has provided the opportunity to use supercritical technology. Supercritical plant is cost effective and is being constructed commercially in many countries, yet still almost half of coalfired power generation plant being built is sub-critical. Integrated gasification combined cycle (IGCC) plant offers potential to produce low emissions, yet only a handful of IGCC plants have been constructed in the past two decades.

The need for energy and the economics of producing and supplying it to the end-user are central considerations in power plant construction and operation. Economic and regulatory conditions must be made consistent with the ambition to achieve higher efficiencies and lower emissions.

I am pleased to publish this report, under my authority as Executive Director, as part of the IEA's role to advise on technologies that have a role in contributing to a sustainable energy future. The views and recommendations expressed do not necessarily reflect the views or policies of IEA member countries.

Maria van der Hoeven

IEA Executive Director 


\section{Acknowledgements}

This report was prepared by the International Energy Agency's Energy Technology Policy Division. Invaluable leadership was provided by Bo Diczfalusy, Director of Sustainable Energy Policy and Technology, and Peter Taylor, Head of Energy Technology Policy Division.

The content of the report reflects contributions from a number of individuals. Thanks go to Sankar Bhattacharya who, before leaving the IEA in 2009, laid the foundation for the report through his extensive research and analysis. Other IEA colleagues provided important contributions, in particular, Kat Cheung, Carlos Fernández Alvarez, Matthias Finkenrath and Osamu Ito, as well as Rebecca Gaghen, Muriel Custodio, Madeleine Barry, Jane Barbière and Betrand Sadin, Marilyn Smith and Simon Watkinson who handled the editing and publication processes, and provided much useful advice.

Thanks are also due to the following experts for their valuable assistance during the preparation and review of this report: Burt Beasley (Australian Coal Association); Stu Dalton (EPRI); Colin Henderson (IEA Clean Coal Centre IA); Takenori Iwasaki (J-Power); Christian Lelong (BHP Billiton); Hans-Joachim Meier (VGB PowerTech); Kyohei Nakamura (J-Power); Hans-Wilhelm Schiffer (RWE); Sanjay Sharma (CEA, India) and Jim Utt (Foster Wheeler). In addition, valuable support was received from members of the IEA Working Party on Fossil Fuels, who provided many helpful comments.

For further information on this document, contact:

Keith Burnard, IEA Secretariat

E-mail: keith.burnard@iea.org 


\section{Executive Summary}

Coal is the world's most abundant and widely distributed fossil fuel, with global proven reserves ${ }^{1}$ totalling nearly 1000 billion tonnes (IEA, 2010a). Given these characteristics, coal has been a key component of the electricity generation mix worldwide. Coal fuels more than $40 \%$ of the world's electricity, though this figure is much higher in many countries, such as South Africa (93\%), Poland (92\%), China (79\%), India (69\%) and the United States (49\%). Moreover, the growing energy needs of the developing world are likely to ensure that coal remains a key component of the power generation mix in the foreseeable future, regardless of climate change policy (IEA, 2010a; IEA, 2010b).

In coal-fired power generation, efficiency is an important performance parameter. Raising efficiency offers benefits such as:

- reduced emissions of carbon dioxide $\left(\mathrm{CO}_{2}\right)$, where a one percentage-point improvement in overall efficiency can result in up to $3 \%$ reduction in $\mathrm{CO}_{2}$ emissions;

- reduced emissions of conventional pollutants; ${ }^{2}$ and

- resource preservation through reduction in consumption of coal.

In the Plan of Action formulated at the G8 Summit at Gleneagles in July 2005, Leaders stated:

We will support efforts to make electricity generation from coal and other fossil fuels cleaner and more efficient by ... supporting IEA work in major coal using economies to review, assess and disseminate widely information on energy efficiency of coal-fired power plants.

This commitment provided the motivation to identify the most promising developments leading to improvements in the efficiency in coal-fired power plants. This report's main objective is to review the major ongoing developments in relevant areas of process technology, equipment, instrumentation and control.

Considerable progress has been made in the development of highly efficient supercritical (SC) and ultra-supercritical (USC) pulverised coal-fired (PC) technology. While sub-critical plants can achieve efficiencies of $38 \%$ to $39 \%$ (LHV, net ${ }^{3}$ ), state-of-the-art USC plants produce a far superior performance. USC plants operating at high steam conditions, with temperatures of $600^{\circ} \mathrm{C}$ to $620^{\circ} \mathrm{C}$ and pressures over $25 \mathrm{MPa}$ ( $250 \mathrm{bar}$ ), result in design efficiencies of $45 \%$ to $46 \%$ (LHV, net) on bituminous coals in some parts of the world. Unit capacity for such plants has reached up to $1100 \mathrm{MWe}$. If ongoing developments in materials are successful, the efficiency of the best PC plants may approach $50 \%$ (LHV, net) in the next 10 to 15 years. Effective policies must be implemented to accelerate such technology developments towards demonstration and deployment stages.

At the same time, progress is being made in the development of circulating fluidised bed combustion (CFBC) plants. These can better utilise low-rank fuels, and result in lower emissions of conventional pollutants. The first supercritical CFBC plant of $460 \mathrm{MWe}$ size was commissioned at Lagisza (Poland) in 2009, and designs for larger units exist. For CFBC, there will continue to be a

\footnotetext{
${ }^{1}$ Proven reserves of coal are the quantity that can be economically mined using current mining technology.

${ }^{2}$ In this context, the term "conventional emissions" applies to sulphur dioxide $\left(\mathrm{SO}_{2}\right)$, oxides of nitrogen $\left(\mathrm{NO}_{\mathrm{x}}\right)$ and particulates.

${ }^{3}$ Efficiency reported on the basis of a fuel's lower heating value (LHV) and net electricity sent-out (net), i.e. LHV, net.
} 
significant market, particularly for lower grade coals, high sulphur coals, opportunity fuels ${ }^{4}$ and biomass. Successful operation of the supercritical unit at Lagisza should pave the way for the construction of such units in other countries, particularly China.

As far as integrated gasification combined cycle (IGCC) power generation is concerned, there are only six coal-based units in the world. However, a small number of new projects has been

Page | 8 initiated worldwide, each at some stage of planning or construction. Some immediate concerns, such as improving the cost and availability of IGCC, must be addressed if the technology is to be more widely deployed. Different supplier groupings have been formed partly to address these concerns and to provide a viable alternative to PC units. These groupings are offering reference IGCC plant designs on a turnkey basis with guarantees on cost, construction time, availability and efficiency, once a design study has been completed. Concerted co-operation among technology vendors and utilities, clarity in emission guidelines and incentives from governments are required for the wider deployment of IGCC. An important factor is that IGCC is well placed technically to capture $\mathrm{CO}_{2}$; though additional costs will be significant, some consider the additional costs may be lower than for pulverised coal systems.

Around $45 \%$ of the world's coal is either high-moisture or high-ash, which often results in inefficiencies in the power plants using these coals. There is a strong need to develop less energyintensive coal-drying technologies. While efforts in coal drying are progressing in Australia, Germany and the United States, accelerating these efforts into large-scale integrated demonstration is important. There is a similar requirement to develop less energy- and waterintensive technologies for coal beneficiation to reduce its ash and sulphur content. Success in developing more efficient coal-drying and beneficiation technologies will promote the wider use of low rank coals in both ultra-supercritical pulverised coal and IGCC applications.

The issue of carbon capture and storage (CCS), which will have significant impact both on existing plants and on plants to be built, is briefly addressed in the report. At the current state of technology, PC or CFBC units retrofitted with $\mathrm{CO}_{2}$ capture will experience an efficiency loss of up to 10 percentage-points. While the concept of "CCS ready" exists, many remaining PC plants may be deemed as unsuitable for retrofit with $\mathrm{CO}_{2}$ capture because the units are too small and/or too inefficient. In general, application of $\mathrm{CO}_{2}$ capture retrofit is expected to be more favourable for plants with a high baseline efficiency. If $40 \%$ efficiency was considered a cut-off for retrofitting with $\mathrm{CO}_{2}$ capture, less than $10 \%$ of the current world coal-fired capacity would lend itself to retrofit with CCS. This calculation assumes that retrofit to these plants would be possible and that acceptable geological storage locations for the captured $\mathrm{CO}_{2}$ exist

Due to decreased efficiency, units retrofitted with CCS will lose exportable generation capacity. New capacity would likely be needed to offset this capacity loss. Based on the information on new builds from around the world, more than $50 \%$ of new plants use either SC or USC technology, and the number is growing. The majority of these plants would probably be suitable for $\mathrm{CO}_{2}$ capture retrofit. It is estimated that by 2030 , up to $30 \%$ of the fleet would be retrofittable, while most of the remaining fleet may not be capture ready, and will require

\footnotetext{
${ }^{4}$ Opportunity fuels are fuels that are not normally used for the purpose but, due to particular circumstances, show potential to be economically and environmentally viable for power generation. Examples typically include fuels that are derived from some sort of waste or by-product, e.g. tyres, plastics and municipal solid waste.

${ }^{5} \mathrm{~A}$ CCS ready facility is a large-scale industrial or power source of $\mathrm{CO}_{2}$ which could be and is intended to be retrofitted with CCS technology when the necessary regulatory and economic drivers are in place. The aim of building new facilities or modifying existing facilities to be CCS ready is to reduce the risk of carbon lock-in or of being unable to fully utilise the facilities in the future without CCS (stranded assets).
} 
assessment for either upgrading to higher efficiency ${ }^{6}$ or complete replacement. The operability and flexibility of plants retrofitted for $\mathrm{CO}_{2}$ capture will need to be assessed, in particular the dynamic performance during start-up, shut-down and load-changing conditions.

Oxy-fuel technology, which can in principle be used with both PC and CFBC units, is undergoing parallel development for $\mathrm{CO}_{2}$ capture. One PC-based pilot unit in Germany ( $30 \mathrm{MWth}$ ), run by Vattenfall, began commissioning in 2008 and is currently being tested. A commercial scale oxyfuel combustion plant, based on the testing results of the pilot plant, is planned for completion by 2015. A $30 \mathrm{MWe}$ PC unit in Australia is currently being retrofitted to use oxy-firing. In 2010, the US Department of Energy (US DOE) announced support to repower a $200 \mathrm{MWe}$ unit in Meredosia, Illinois with advanced oxy-fuel technology as part of the FutureGen 2.0 Alliance.

Regarding the choice of IGCC, PC and CFBC, one issue of particular importance is the method for selection of new power plants. While there are several proposals for further commercial demonstrations of IGCC and some are being constructed, SC and USC pulverised coal plants continue to dominate new plant orders. It is possible that IGCC, with or without CCS, may penetrate the market on a large scale only where the co-production of power and chemicals can be economically demonstrated.

The main objective of this report is to summarise the major ongoing developments in process technology, equipment, instrumentation and control that are expected to result in improved efficiency in new coal-fired plants. Key research and development (R\&D) requirements for technologies are identified. Barriers to the successful demonstration of technologies and to their wider deployment are also addressed.

\footnotetext{
${ }^{6}$ Incremental increases to the efficiency of an existing coal-fired power plant are possible by a number of means, depending on the particular status of the original plant, by e.g. upgrading components, improving operational practices or improving the quality of the coal. It should be noted, however, that to go from sub-critical to supercritical steam conditions would require replacement of the boiler and the steam turbine, i.e. repowering of the plant.
} 


\section{Key recommendations}

\section{Page Recommendation}

11 Large-scale supercritical pulverised coal plants are commercially available and cost effective. Strong consideration should be given to the introduction of policies that markedly reduce the future construction of sub-critical plant for new build.

15 Following the successful commissioning of the first supercritical CFBC at Lagisza (Poland), it should serve as an example for future CFBC plants. In fact, both China and Russia now have programmes to construct supercritical CFBC units.

25 Maximising plant efficiency is highly desirable when employing CCS. Efficiency gains from upgrading sub-critical units are limited. To achieve efficiencies higher than $40 \%$ (LHV, net), operation with supercritical steam conditions is necessary. If, at some future time, CCS is to be applied to most coal-fired plant, policies will need to address the status of less efficient power generation.

26 The energy penalty associated with capturing $\mathrm{CO}_{2}$ from a coal-fired power plant is a barrier to deployment. There are prospects in the long term for reducing this energy penalty. For IGCC, for example, there are prospects to reduce the penalty to perhaps around 4 percentage-points by use of innovative systems, such as membrane reformer reactors; where reforming, shift and $\mathrm{CO}_{2}$ capture would be carried out in a single reactor.

33 A significant part of the world's coal reserves comprises brown coal or lignites, often associated with high moisture content. This can lead to a penalty of between 4 and 9 percentage-points in plant efficiency. RWE employs a novel coal-drying process at Niederaussem Unit $K$, where an efficiency of $43.5 \%$ (LHV, net) has been achieved. Improvements under development may lead to an increase of a further 4 percentage-points. This work sets a benchmark for what may be achieved using low-grade coals. 


\section{Developments in Process Technology}

Employing the combustion of PC in air to raise steam has been the mainstay of coal-based power generation worldwide for almost 100 years. The efficiency of a PC combustion unit depends on a variety of factors: steam conditions, the quality of coal used, ambient conditions, plant design, and operational and maintenance practice. A number of advanced coal-fired power generation technologies, cleaner coal technologies (CCTs), as they are often called, have been or are being developed to improve thermal efficiency, to reduce and capture $\mathrm{CO}_{2}$ emissions, and to reduce other emissions (e.g. $\mathrm{NO}_{x}, \mathrm{SO}_{2}$ and particulates).

The major coal-based power generation technologies available today, and/or under development, include:

- Supercritical (SC) and ultra-supercritical (USC) PC combustion

- Circulating fluidised bed combustion (CFBC)

- Integrated gasification combined cycle (IGCC)

This section briefly reviews these CCT options for power generation and the status of developments aimed at efficiency improvement. It also identifies barriers to their developments and deployment. All these technologies can potentially be used with carbon capture and storage (CCS) retrofit. A separate sub-section, therefore, deals with the 'capture readiness' of these technologies.

\section{Supercritical and ultra-supercritical pulverised coal-fired technology}

\section{The supercritical cycle}

The efficiency of a steam cycle is influenced by, among other factors, the pressure and superheat and reheat temperatures of the steam. Supercritical is a thermodynamic expression where there is no distinction between the liquid and gaseous phase. Water/steam reaches this state at about $22.1 \mathrm{MPa}$ (221 bar) pressure. Above this operating pressure of the steam, the cycle is supercritical and its cycle medium is a single-phase fluid; as a result there is no need to separate water from steam as in the boiler of a sub-critical cycle. Once-through boilers are therefore used in a supercritical cycle.

Typical sub-critical steam cycle operating parameters are from 150 to 180 bar pressure and between $540^{\circ} \mathrm{C}$ and $565^{\circ} \mathrm{C}$ temperature for superheated steam, with reheat ${ }^{7}$ to similar temperatures. Steam cycle operating parameters for SC plants typically are 245 bar pressure and $540^{\circ} \mathrm{C}$ to $570^{\circ} \mathrm{C}$ for superheated steam, with reheat to similar temperatures. USC plants operate at steam temperatures of around $600^{\circ} \mathrm{C}$ or higher at present. A switch from sub-critical to current USC steam conditions would raise efficiency by around 4 to 6 percentage-points.

\section{Current commercial status}

For low to moderate ash coals, both supercritical and ultra-supercritical units are available from major boiler and turbine suppliers. These units run around 260 bar main steam pressure and

\footnotetext{
${ }^{7}$ Superheated steam is passed into the high pressure steam turbine. Exhaust steam from the high pressure steam turbine exhaust is routed back to the boiler to be reheated prior to being passed again into the steam turbine.
} 
steam temperatures up to $620^{\circ} \mathrm{C}$ for reheat steam, slightly lower for main steam. For high-ash coals, supercritical units are beginning to be introduced in India. Operating experience at India's Sipat and Barh plants, and the new units to be built as part of the Ultra Mega projects, are expected to open the way for wider use of SC units in both India and other countries that rely on high-ash coals for power generation, such as Bulgaria, regions of China, Poland, Romania and South Africa. In fact, major efforts are being made to introduce supercritical technology into India; about 50\% of the incremental coal fired capacity addition between 2012 and 2017 is expected to comprise of supercritical units (Sharma, 2011). Being more efficient and commercially available, it is imperative to make supercritical units as 'minimum standard' in the near future for new-builds and replacements, local demand and grid conditions permitting.

\section{Location of SC and USC units}

Supercritical technology is already used in a number of countries and has become the norm for new plants in industrialised countries. Supercritical plants are currently located in eighteen countries, where their share in coal-fired power generation in those countries varies (Figure 1). Globally between 2004 and mid-2007, the share of SC plants increased from approximately $18 \%$ to $20 \%$ ( $265 \mathrm{GW}$ ) of coal-fired capacity. This rose to over $25 \%$ in 2009 and increased further as new SC units were built in China, India, South Africa and Russia. New SC plants are being built in the United States for the first time since 1992. Two new units totalling $1470 \mathrm{MWe}$ were commissioned in 2008, an $800 \mathrm{MWe}$ unit was commissioned in 2009, and a further $800 \mathrm{MWe}$ unit was to be commissioned in 2010.

Figure 1 Location of advanced PCC plants and their share in coal-fired power generation

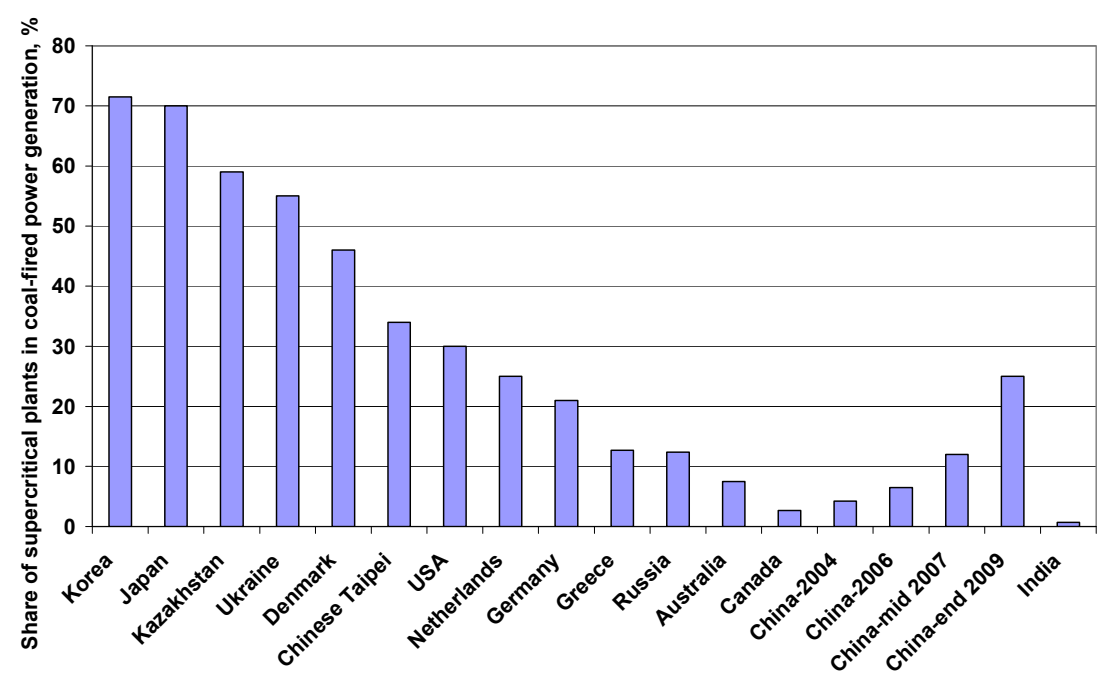

Source: Unless otherwise indicated, material in figures and tables derive from IEA data and analysis.

USC plants are in operation in Denmark, Germany, Japan and Italy; however their share of global power generation is under $1 \%$. A number of USC plants are also being constructed in China. An example is the Huaneng Group's Yuhuan Power plant in Zhejiang Province, which is a USC plant with two $1000 \mathrm{MWe}$ units and steam parameters of $26.25 \mathrm{MPa} / 600^{\circ} \mathrm{C} / 600^{\circ} \mathrm{C}$. Chinese manufacturers are also offering USC at up to $605^{\circ} \mathrm{C}$, i.e. at or near state-of-the-art conditions (Minchener, 2010). 
While the first generation of supercritical units was under $400 \mathrm{MWe}$ in size, larger units of up to $1100 \mathrm{MWe}$ are progressively being built. The major units, built under construction or under planning in different countries, clearly demonstrate the progression to larger unit sizes (Table 1).

Table 1 Major supercritical units - recently commissioned, under construction or planned

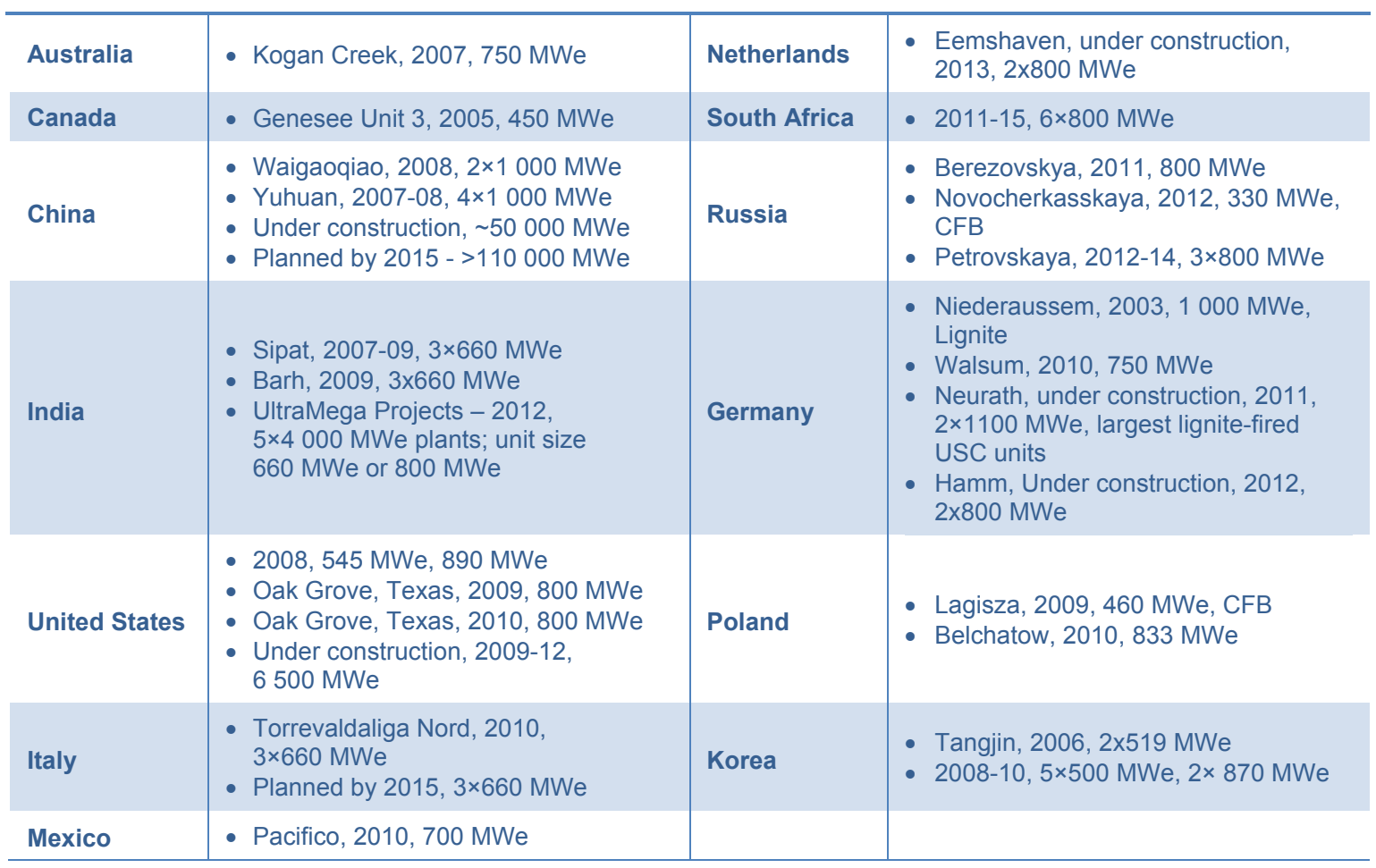

Note: All are PC combustion plants unless otherwise noted.

\section{Box 1 Sliding pressure operation}

Sliding pressure operation maintains high efficiency at part load for supercritical plants. Load cycling is often inevitable in power plant operation to meet changing grid demands. However, boiler and turbine efficiency drops off during operation at partial loads, by as much as $2 \%$. New supercritical boilers are mostly capable of sliding pressure operation. By adopting the sliding pressure operation with lower boiler pressures, the plant efficiency can be maintained at partial loads due to: 1 ) improvement of high pressure (HP) turbine efficiency; 2 ) reduced auxiliary power consumption by boiler feed pumps; and 3) higher steam temperature at the HP turbine outlet. As well as efficiency advantages, there are other benefits such as reduction in start-up time, increase in load-ramp rate and an improved lifespan of high-pressure steam bypass valves.

The first North American sliding-pressure enabled boiler was commissioned in Genesee Unit 3, Canada in 2005 and some of the recent units built in China are also capable of sliding pressure operation. It is likely that a significant proportion of the new large units built in China will be capable of sliding-pressure operation. Load-following capability of the new generation of units will reduce coal consumption per unit output and improve overall efficiency. 


\section{Cost implications}

Estimates suggest that USC plants will reduce fuel consumption and emissions by $25 \%$ to $30 \%$ compared to the current state-of-the-art sub-critical cycle (Dalton, 2006).

Boiler and steam turbine costs can be as much as $40 \%$ to $50 \%$ higher for a USC plant than for a sub-critical plant (ETP 2008). However, the balance-of-plant cost can be $13 \%$ to $16 \%$ lower, because of reductions in coal consumption, coal handling and flue gas handling. The total investment cost for USC steam cycle plants can be $12 \%$ to $15 \%$ higher than the cost of a subcritical steam cycle.

\section{Barriers to widespread adoption of supercritical units}

The first supercritical unit, Eddystone 1, was built in the United States in 1959. Originally designed to run at 345 bar and $650 / 650 / 650^{\circ} \mathrm{C}$ in a double reheat cycle, the unit faced problems of low availability resulting from material issues and problems that are typical of 'first-of-its-kind' developments. The unit is now operated at 243 bar and $565 / 565^{\circ} \mathrm{C}$. The initial difficulties, plus the costs of further development and the relatively low price of coal, resulted in a lack of interest in SC technology among the utilities, most of which returned to more reliable sub-critical units. However, such problems are now largely eliminated. But, SC and USC technology can sometimes be rejected or overlooked because of misguided perceptions that they are costly, unproven and unsuitable for use with local coals. Consequently, many countries have preferred conventional sub-critical technology despite evidence that demonstrates that SC and USC designs are commercially proven and competitive, especially when coal prices are high, as they have been in the recent past. Experience is lacking only in the case of high-ash coals; but even for such coals, there should be a gradual switch from sub-critical to SC and then to USC as operational experience grows and the initial difficulties, if any, are resolved.

\section{Further development of USC conditions}

Ultra-supercritical units operating at temperatures of $700^{\circ} \mathrm{C}$ and higher, and pressure in excess of $300 \mathrm{bar}$ are in the development phase. They will use nickel-based super-alloys for some components in the boiler, turbine and piping. Such materials are already used in gas turbines. However, the operating environment with flue gas from coal is different so international programmes are seeking to develop the necessary materials and fabrication methods for use with these materials (IEA, 2007). These programmes are:

- two EC-supported projects; i.e. AD700, which was superseded in 2004 by COMTES700. The latter project (Gierschner, 2008) aims to raise the main steam temperature and pressure to $700^{\circ} \mathrm{C}$ and up to $375 \mathrm{bar}$, with a reheat temperature of up to $720^{\circ} \mathrm{C}$. [Note: Due to delays in technology development, the construction of a full-scale demonstration, in the form of a 500 MWe unit at Wilhelmshaven, Germany, was recently postponed (Topper, 2011). Steam conditions were to have been $35 \mathrm{MPa} / 700^{\circ} \mathrm{C} / 720^{\circ} \mathrm{C}$, with the aim of achieving an efficiency of at least $50 \%$ LHV-, assisted by cold sea-water cooling. At the moment, it is unclear when this development will be resumed.]

- the US DOE-led programme on 'Advanced materials for Ultra-supercritical boiler systems', which aims to raise the steam temperature to $760^{\circ} \mathrm{C}\left(1400^{\circ} \mathrm{F}\right)$, and pressure up to 375 bar (Dalton, 2006). 
If successful, USC conditions will raise power plant efficiency to over 50\% (LHV, net) with bituminous coal, and also over $50 \%$ (LHV, net) with integrated, pre-drying for high-moisture lignite.

\section{Implications of USC developments on $\mathrm{CO}_{2}$ capture}

Adding $\mathrm{CO}_{2}$ capture to a power plant results in a substantial energy penalty. As large volumes of absorbent are required to treat the flue gas, its subsequent regeneration uses considerable quantities of low pressure steam that would otherwise be available for power generation. Maximising plant efficiency is, therefore, highly desirable when employing CCS: the higher the net efficiency of the base plant, the higher will be the net efficiency of that plant with CCS.

\section{Barriers to further advances in USC conditions}

The major barriers to advances in SC and USC steam cycles are therefore technical, i.e. metallurgical and material fabrication issues. Apart from the continued development of materials, fabrication methods and long-duration testing of materials, there is clearly a need to accelerate the development and full-scale demonstration of advanced USC conditions.

\section{Circulating fluidised bed combustion technology}

There are two major categories of fluidised bed combustion units: those operating with bubbling fluidised bed combustion (BFBC) and those with circulating fluidised bed combustion (CFBC). Almost all of the recent plant additions have been CFBC units. CFBC units can tolerate a wide variety of coals and particle sizes and, because of their low operating temperatures and staged combustion, produce low levels of $\mathrm{NO}_{x}$ relative to $\mathrm{PC}$ boilers. The lower operating temperature is also ideally suitable for the in situ capture of sulphur dioxide $\left(\mathrm{SO}_{2}\right)$. The efficiency of CFBC units is similar to that of PC units.

The largest operating sub-critical CFBC unit is of $320 \mathrm{MWe}$ at Jacksonville, Florida. Units of a similar size also operate in China. Total CFBC plant capacity globally is around $20 \mathrm{GW}$, and is expected to grow. Previously only available in sub-critical designs, CFBC technology has now reached an economic scale for supercritical conditions. The first supercritical CFBC unit (460 MWe, 282 bar $/ 563^{\circ} \mathrm{C} / 582^{\circ} \mathrm{C}$ ) was located at Lagisza (Poland). Designed by Foster Wheeler, this plant is operating and has a design efficiency of $43.3 \%$ (LHV, net) on Polish lignite. A second supercritical CFBC unit, a 330 MWe capacity, will be located at the Novocherkasskaya GRES facility in Russia (Jantti et al, 2009). It was also encouraging to see that a major guideline in China's 11th five-year plan was to build large-scale CFBC units.

There has been a marked increase in the capacity of CFBC units over recent years (Figure 2). Designs for supercritical units of $600 \mathrm{MWe}$ and $800 \mathrm{MWe}$ capacity are now complete (Utt, 2011). However, given the lower operating temperatures of CFBC units, considerable design improvement will be required for USCs needing much higher than $600^{\circ} \mathrm{C}$ superheat or reheat temperatures. If such temperatures, together with a steam pressure of $28 \mathrm{MPa}$, are achieved, units will reach an efficiency of over $45 \%$ (LHV, net) or $43 \%$ (HHV,net) for hard coal. 
Figure 2 CFBC scale up chronology

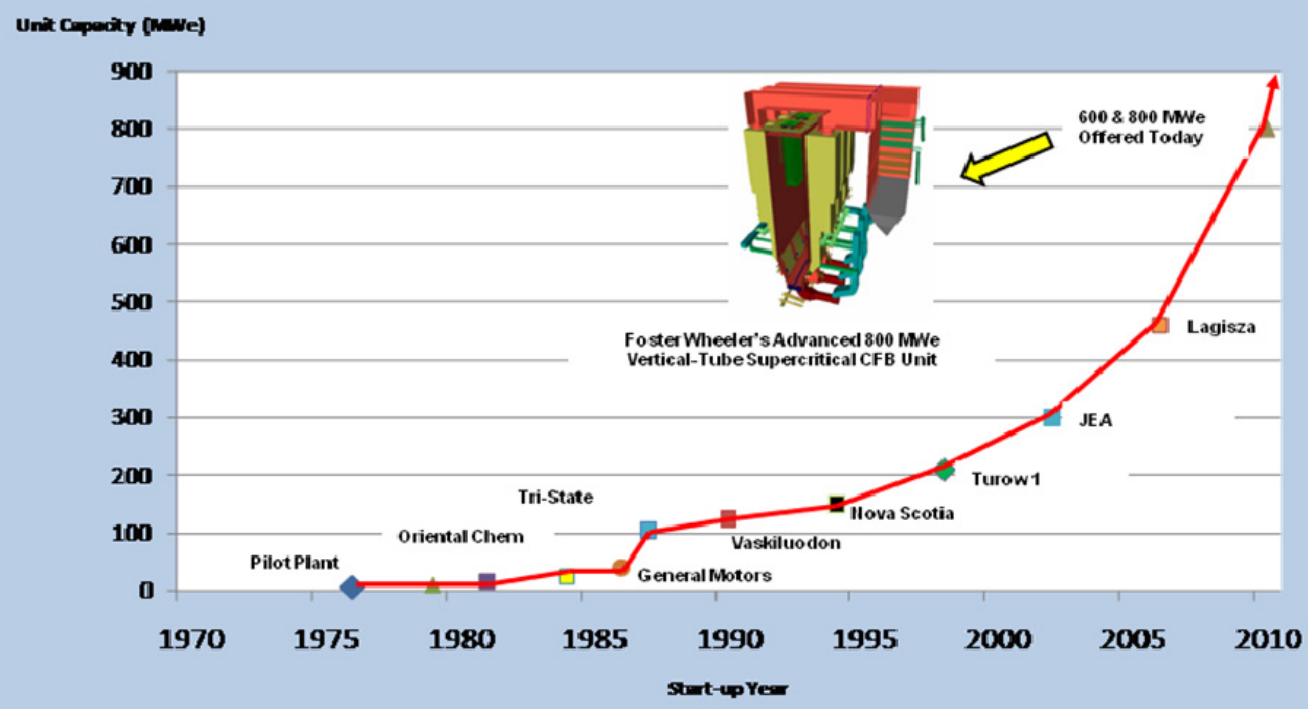

Source: Utt, 2011.

\section{Barriers to wider adoption of CFBC technology}

With around $20 \mathrm{GW}$ operating worldwide, CFBC units can demonstrate significant operating experience. They have the ability to accept a variety of fuels, including a range of coals: from lignites to anthracite, waste coal and biomass. They exhibit low emissions of conventional pollutants and show potential to be designed for oxy-firing. Though there is a need for research, development and demonstration (RD\&D) to progress to higher steam conditions over time, there are no obvious barriers to CFBC other than the size of the market.

R\&D needs for development of supercritical CFBC technology

The major development needs for supercritical CFBC technology are mostly similar to those for SC and USC pulverised coal-fired technology. These are:

- develop materials with higher temperature and pressure resistances;

- improve fabrication technology using these materials; and

- accelerate demonstration of large SC units.

\section{Integrated gasification combined cycle}

Coal-based IGCC uses a combination of gas and steam turbines to produce electricity. The gas used to fire the gas turbine is first made by "gasifying" or partially oxidising the coal to produce a fuel gas, which is then followed by gas cleaning as shown in Figure 3. 
Figure 3 Major components of an IGCC system without $\mathrm{CO}_{2}$ capture

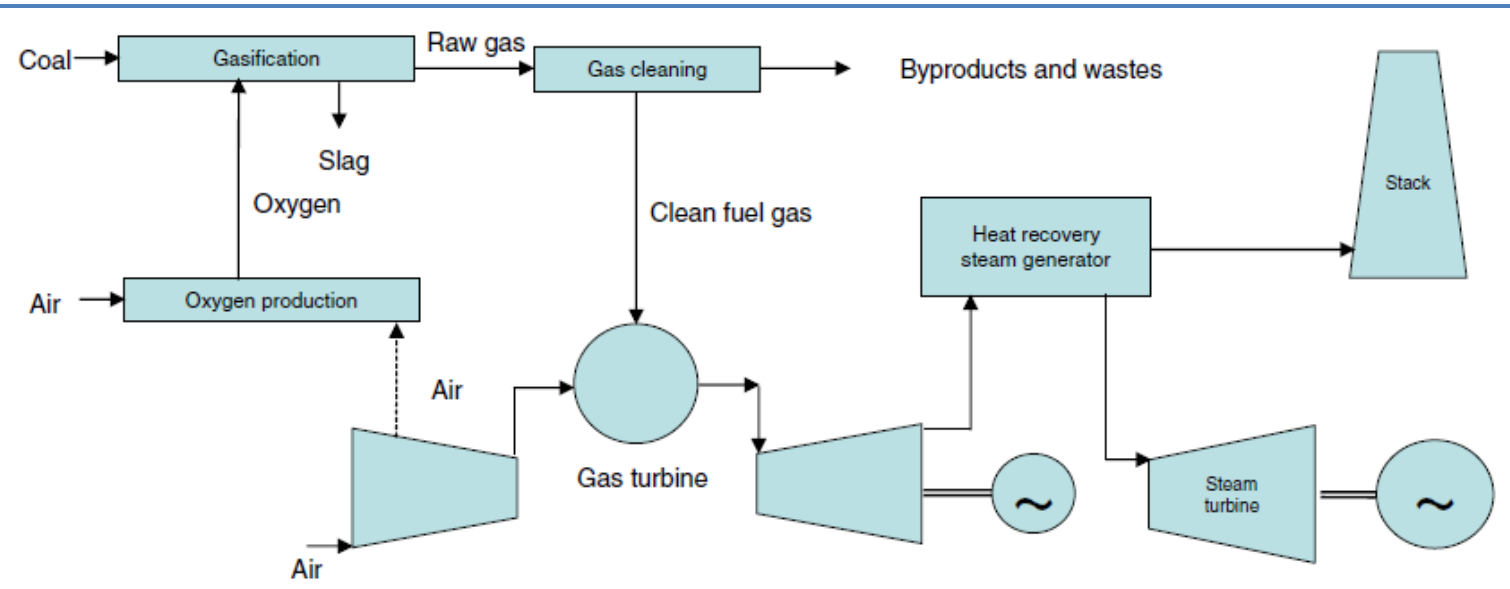

Source: Henderson, 2008.

The major subsystems within IGCC that have the potential to influence the overall efficiency, cost and reliability, are:

- gasifier - this affects the conversion of carbon in coal to fuel gas

- gas cleaning system - this affects the emission of pollutant gases and gases harmful to either the environment, the gas turbine or both;

- oxygen production;

- gas turbine;

- syngas cooler, heat recovery steam generator, steam turbine cycle.

At present, many gasification plants use a variety of fuels for chemical production, but only six coal-based IGCC plants are in operation. These are:

- Buggenum plant in the Netherlands using Shell technology. 253 MWe (net). Started in 1994 with a dry-feed $\mathrm{O} 2$-blown gasifier and $1060^{\circ} \mathrm{C}$ gas turbine;

- Elcogas plant in Puertollano, Spain using Prenflo technology. 300 MWe (net). Started in 1998 with a dry-feed 02 -blown gasifier and $1120^{\circ} \mathrm{C}$ gas turbine; the plant uses a mix of petcoke and coal;

- Nakoso plant in Japan using Mitsubishi technology. 250 MWe (gross). Started in 2007 with a dry-feed air-blown gasifier and $1200^{\circ} \mathrm{C}$ gas turbine;

- Tampa Electric plant in Florida, United States, using GE Technology. 250 MWe (net). Started in 1996 with a slurryfed O2-blown gasifier and $1200^{\circ} \mathrm{C}$ gas turbine;

- SUV/EGT plant in Czech Republic. 350 MWe (net). Started in 1996 using Lurgi Dry Ash technology.

- Wabash River IGCC repowering project in Indiana, United States, using E-GAS technology. $262 \mathrm{MWe}$ (net). Started in 1995 with a slurry-fed O2-blown gasifier and $1200^{\circ} \mathrm{C}$ gas turbine;

Other plants are either planned or under construction in China and the United States. The net efficiency for existing coal-fired IGCC plants is around 42\% (LHV, net). NUON's Shell coal gasification process-based IGCC plant at Buggenum (the Netherlands) achieved up to $43 \%$ (LHV) on bituminous coals, which is equivalent to $41 \%$ (HHV). Commissioning began in 1993, with a V94.2 gas turbine and a turbine inlet temperature for natural gas of around $1060^{\circ} \mathrm{C}$. In theory, 
and depending on the choice of gasifier, a modern, high temperature, F-class gas turbine should produce an efficiency of $46 \%$ to $47 \%$ net (LHV, net) or $44 \%$ to $45 \%$ (HHV, net) using bituminous coals. There are a number of major coal-based IGCC projects under consideration around the world (Table 2). It is interesting to note that the large majority of projects are based on entrained flow gasifiers.

Table 2 Major coal-based IGCC projects under consideration

\begin{tabular}{|c|c|c|c|c|c|c|}
\hline Project & Location & Coal & $\begin{array}{c}\text { Gasifier } \\
\text { Technology }\end{array}$ & $\begin{array}{l}\text { Gas turbine } \\
\text { and model }\end{array}$ & $\begin{array}{l}\text { Net output } \\
\text { (MWe) }\end{array}$ & Year \\
\hline GreenGen & $\begin{array}{l}\text { Tianjin } \\
\text { China }\end{array}$ & Bit & $\begin{array}{l}\text { Shanghai } \\
\text { boiler; } \\
\text { dry fed O2 } \\
\text { blown }\end{array}$ & $\begin{array}{l}\text { Siemens and } \\
\text { Shanghai } \\
\text { Electric }\end{array}$ & $\begin{array}{l}250 \text { - stage } 1 \\
400 \text { - stage } 2\end{array}$ & $\begin{array}{l}\text { Late } 2011 \\
\text { [Stage 1] }\end{array}$ \\
\hline $\begin{array}{l}\text { Dongguan } \\
\text { Taiyangzhou }\end{array}$ & $\begin{array}{l}\text { Guangdong } \\
\text { China }\end{array}$ & Bit & $\begin{array}{l}\text { KBR Transport } \\
\text { Integrated } \\
\text { Gasification }\end{array}$ & Unknown & $\begin{array}{l}120 \text { - stage } 1 \\
800 \text { - stage } 2\end{array}$ & $\begin{array}{l}\text { Late 2011 } \\
\text { [Stage 1] }\end{array}$ \\
\hline Duke Energy & $\begin{array}{l}\text { Indiana } \\
\text { US }\end{array}$ & Bit & $\begin{array}{l}\text { GE } \\
\text { Slurry-fed O2 } \\
\text { blown }\end{array}$ & $\begin{array}{l}\text { GE } \\
\text { Frame 7B }\end{array}$ & 618 & 2012 \\
\hline $\begin{array}{l}\text { Nuon } \\
\text { Magnum }\end{array}$ & $\begin{array}{l}\text { Eemshaven } \\
\text { Netherlands }\end{array}$ & $\begin{array}{l}\text { Bit } \\
\text { Biom }\end{array}$ & Shell & $\begin{array}{l}\text { MHI } \\
\text { 3xM701F4 }\end{array}$ & 1200 & 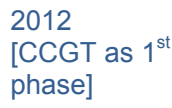 \\
\hline $\begin{array}{l}\text { Excelsior } \\
\text { Energy }\end{array}$ & $\begin{array}{l}\text { Minnesota } \\
\text { US }\end{array}$ & Lig/PetCoke & $\begin{array}{l}\text { ConocoPhillips } \\
\text { Slurry-fed O2 } \\
\text { blown }\end{array}$ & $\begin{array}{l}\text { Siemens } \\
2 \text { xS5000F }\end{array}$ & 620 & $\begin{array}{l}2014 \\
\text { [No PPA, as } \\
\text { yet] }\end{array}$ \\
\hline $\begin{array}{l}\text { Southern } \\
\text { Company }\end{array}$ & $\begin{array}{l}\text { Mississippi } \\
\text { US }\end{array}$ & Lig & $\begin{array}{l}\text { KBR Transport } \\
\text { Integrated } \\
\text { Gasification }\end{array}$ & $2 \times$ 'F' Class & 582 & 2014 \\
\hline $\begin{array}{l}\text { Texas Clean } \\
\text { Energy } \\
\text { Project } \\
\text { (TCEP) }\end{array}$ & $\begin{array}{l}\text { Texas } \\
\text { US }\end{array}$ & Sub-bit & Siemens & Siemens & 380 & 2015 \\
\hline $\begin{array}{l}\text { Wandoan } \\
\text { Power }\end{array}$ & $\begin{array}{l}\text { Queensland } \\
\text { Australia }\end{array}$ & Bit & GE & GE & 334 & 2016 \\
\hline $\begin{array}{l}\text { Osaki } \\
\text { CoolGen }\end{array}$ & Japan & Sub-bit & Hitachi & Hitachi & 140 & 2017 \\
\hline $\begin{array}{l}\text { Hydrogen } \\
\text { Energy } \\
\text { California } \\
\text { (HECA) }\end{array}$ & $\begin{array}{l}\text { California } \\
\text { US }\end{array}$ & Bit/pet coke & GE & $\begin{array}{l}\text { GE } \\
\text { Frame 7F }\end{array}$ & 250 & 2018 \\
\hline $\begin{array}{l}\text { American } \\
\text { Electric } \\
\text { Power }\end{array}$ & $\begin{array}{l}\text { Ohio } \\
\text { US }\end{array}$ & Bit & $\begin{array}{l}\text { GE } \\
\text { Slurry-fed O2 } \\
\text { blown }\end{array}$ & $\begin{array}{l}\text { GE } \\
\text { Frame 7B }\end{array}$ & 630 & $\begin{array}{l}\text { [Project on } \\
\text { hold] }\end{array}$ \\
\hline $\begin{array}{l}\text { Taylorville } \\
\text { Energy } \\
\text { Center }\end{array}$ & $\begin{array}{l}\text { Illinois } \\
\text { US }\end{array}$ & Bit & Siemens & GE & 600 & $\begin{array}{l}\text { [Project on } \\
\text { hold] }\end{array}$ \\
\hline
\end{tabular}

\section{Gasifier system}

There are three major types of gasifier suitable for IGCC application:

- entrained flow gasifier. With both dry (e.g. Shell, Siemens, Mitsubishi) and wet slurry (e.g. GE, ConocoPhillips) feeding, these entrained flow gasifiers require fine particle sizes, are suitable for all types of coals and operate at temperatures above the melting point of ash. (Note: if coals with a high melting point are selected, flux addition may be required to facilitate 
melting and ash discharge). As a result, conversion of the carbon to fuel gas is nearly complete. With the exception of the Mitsubishi gasifier, they are all oxygen-blown.

- gasifier. These require large particle sizes for effective fluidisation and operate at around $900^{\circ} \mathrm{C}$, i.e. below the melting point of ash. They are particularly suitable for highly reactive, non-caking coals, such as lignites. As a result of the lower operating temperatures, carbonconversion is often within the $80 \%$ to $90 \%$ range. gasifiers can be both air or oxygen-blown.

- transport gasifier. Developed by KBR, it is a hybrid between entrained flow and gasifiers. It can handle both lignites and bituminous coals, and operates at slightly higher temperatures than fluidised bed gasifiers.

Entrained flow gasification technology currently dominates; the fluidised bed and transport gasifier types have not yet been demonstrated for commercial-scale pressurised gasification conditions.

Other types of novel gasifiers proposed or under development include:

- the Pratt and Whitney Rocketdyne gasifier, which results in a cost-saving, small size unit;

- a chemical looping gasifier that avoids the need for an energy-consuming air separation plant;

- a membrane gasifier, combining gasification and oxygen separation in one step.

Both high-ash and high-moisture coals present problems in gasification. High-ash coals produce excessive amounts of molten ash inside the entrained flow gasifier, which creates operational problems and results in an efficiency penalty. These coals would be better gasified in a lower temperature gasifier, such as the fluidised bed gasifier. To maintain fluidisation and prevent a build-up of agglomerating material, the bed has to be drained of ash regularly, which also results in loss of solid carbon matter.

Likewise, it is not easy to use low-grade, high-moisture coals directly in slurry-feed entrained gasifiers. The high porosity and oxygen content of these coals give rise to difficulties in slurry preparation. The conventional alternative, of pre-drying plus conventional lock-hopper based feeding, reduces efficiency. Continuous dry-feeding systems (solids pumps) for introducing highmoisture coals directly to the gasifier could help and at the same time, bring benefits in efficiency i.e. reduced oxygen demand and reduced wear on gasifier injectors (Henderson, 2008).

The issues of coal gasification in general and IGCC in particular have been extensively addressed in two reports (Henderson, 2008; Fernando, 2008).

\section{Gas-cleaning system}

Gas cleaning is required to rid the fuel gas of solid and gaseous pollutants, including trace metals, ammonia, sulphur gases, chlorides, and mercury, which are harmful to the gas turbine downstream.

Gas cleaning at a high temperature, or "hot gas cleaning", is preferable, as this preserves the energy content of the fuel gas. However, hot gas cleaning on a commercial scale has yet to be developed for reliable, continuous operation.

Dry scrubbing is used mainly for the control of trace metals and sulphur gases, while wet scrubbing is preferred to control ammonia and chloride species (Henderson, 2008). 


\section{Gas turbine system}

The efficiency of an IGCC system depends on the outputs from the combined cycle, i.e. from the gas turbine and from the steam cycle. The power produced by the gas turbine contributes around $60 \%$ of the gross electricity generated in an IGCC plant. The efficiency of the gas turbine depends on a number of factors, including its inlet temperature.

Early difficulties were encountered with the combustion of syngas in gas turbines. For European IGCCs, these problems were solved by modifications to the silo combustors (Goudappel and Berkhout, 2006). The Siemens V94.2 gas turbine at the Buggenum IGCC plant has a turbine inlet temperature on natural gas of around $1060^{\circ} \mathrm{C}$.

F-Class turbines operating with inlet temperatures around $1400^{\circ} \mathrm{C}$ are currently being used with natural gas as a fuel in both open-cycle and combined-cycle configurations. Examples of the most advanced, partially steam-cooled turbine designs that use even higher firing temperatures (up to $1500^{\circ} \mathrm{C}$ ) are GE's H-class turbine and the G-class machines from MHI and Siemens-Westinghouse. All major suppliers of gas turbines currently offer machines for syngas up to F-class. Versions based on the latest classes for natural gas will gradually be adapted for use with coal-fuelled IGCCs. Depending on the fuel composition, for F-class gas turbines to operate on syngas, some de-rating might be required in firing temperatures to cope with the higher steam content in combustion gas. In addition, combustor design modifications and a redesign of the turbine inlet section might be needed, compared to a natural gas fired gas turbine for emissions compliance, to provide a larger gas turbine swallowing capacity. Though no coal-based IGCC is yet operating on an FB or equivalent turbine, it is planned that the Duke Energy Edwardsport IGCC in the United States, which is scheduled to start up in 2012, will have an FB turbine. Future turbine improvements have the potential to increase IGCC efficiencies by 3 to 5 percentage-points (Anand et al., 2006).

\section{Gas turbines for high-hydrogen fuels}

A high combustion temperature and increased emissions of $\mathrm{NO}_{x}$ are the undesirable side-effects of burning fuel gas containing high concentrations of hydrogen. $\mathrm{NO}_{x}$ control in gas turbines is achieved by diluting the syngas with nitrogen or steam to limit peak flame temperature. This is a standard safety procedure for diffusion combustors. This is also the case for the combustion of high hydrogen-containing gas. A disadvantage of diffusion combustors is that they produce considerably more $\mathrm{NO}_{x}$ than the premix combustors used for natural gas and distillate fuels and this is exacerbated when burning fuel gas with high hydrogen content. This is typical of IGCC plants with $\mathrm{CO}_{2}$ capture.

Currently, industrial gas turbines firing hydrogen at refineries use up to E-class technology (designed for $1100^{\circ} \mathrm{C}$ firing temperature on natural gas). However, GE offers IGCC based around the GE-Bechtel Alliance reference plant with a 7FB gas turbine (or 7F Syngas turbine) that will be $\mathrm{CO}_{2}$ capture-ready without requiring modifications to the hot gas path of the gas turbine. Natural gas combined cycle projects using modern gas turbines are also being offered or constructed for subsequent conversion to IGCC with $\mathrm{CO}_{2}$ capture. Temperatures will probably be reduced when CCS is added, at least until ongoing R\&D allows the use of higher temperatures.

Major research programmes have resulted in improvements to gas turbines (Smith, 2009). Notably, the Advanced Hydrogen Turbines programme and the Enhanced $\mathrm{CO}_{2}$ Capture project (ENCAP) of the European Commission (EC) have supported gas turbine manufacturers over the years in developing high efficiency turbines. More recently, the EC co-funded a research and demonstration project, 'Low emission gas turbine technology for hydrogen-rich syngas' (or 
H2-IGCC), which began in 2009. This project is investigating gas turbine technologies that enable the burning of undiluted syngas in IGCC.

Gas turbines firing high concentrations of hydrogen do not currently have an air extraction capability to supply air to the air separation plant. Some manufacturers are working to develop this feature (Hannemann et al., 2005). Although air supply integration can create its own difficulties, air extraction does provide a means of limiting the surge in flow that would otherwise arise from the much higher flow rate within the turbine section for syngas compared with high calorific value fuels.

\section{Outlook for coal-based IGCC}

Aided by climate change mitigation pressures and technical and cost improvements, IGCC has the potential, in the longer term, to compete with PC combustion technology, the current system of choice for utilities. However, the immediate future of the technology is less certain.

As indicated in Table 2, several IGCC projects have been proposed in Australia, China, the European Union and the United States, with a number of other countries showing interest. Of around $25500 \mathrm{MW}$ IGCC projects proposed worldwide in 2007, the majority were later cancelled, citing cost escalations and uncertainty in emission regulations. Of note is that $60 \%$ of the projects were in the United States, greatly helped by the provisions of the 2005 Energy Policy Act.

Immediate concerns must be addressed if IGCC is to be more widely deployed. Though proponents of IGCC may point to particular benefits, such as emissions performance or potential for polygeneration, it is still perceived to have as of yet unquantified operating risks. Operation and maintenance costs are less certain as there are few reference plants and little power industry operating experience. Other issues include improving the capital cost and availability of IGCC on all coals. In response to these concerns, and to provide a viable alternative to PC combustion units, various supplier groupings have been formed that offer reference IGCC plant designs on a turnkey basis with guarantees on cost, construction time, availability and efficiency. Notable examples of these groupings, joint ventures and acquisitions are:

- GE-Bechtel;

- Siemens-Fluor;

- Mitsubishi-Siemens, for both gas turbines and gasifier technology;

- Shell-Krupp Uhde-Black \& Veatch;

- Southern-KBR, for new technology pitched directly at sub-bituminous and lignite market;

- ConocoPhillips-Fluor;

- BP-Rio Tinto;

- GE's acquisition of Stamet Pumps (a dry solids pumping system) to extend its offering to highmoisture coals.

Some power utilities still perceive IGCC to be complex but when CCS becomes a requirement, using IGCC with PC technologies may be more efficient than deploying flue gas scrubbing based $\mathrm{CO}_{2}$ capture, as indicated by various studies (Henderson, 2009).

Concerted co-operation among technology vendors and utilities, clarity in emission guidelines and incentives from governments are required for wider deployment of IGCC. 


\section{R\&D requirements to accelerate IGCC deployment}

The major and immediate needs for wider deployment of IGCC are:

- demonstration of increased availability and reliability for all types of coals;

- demonstration of quench gasifier for low-grade coals;

Page | 22 - optimisation of existing and/or development of new dry-feed systems, and reliable feeding systems for high-moisture, low- grade coals;

- demonstration of reliable multi-pollutant gas clean-up systems with low energy penalty;

- demonstration of large gas turbines within a coal-fuelled IGCC plant burning fuel gas containing high concentrations of hydrogen;

- online monitoring of refractory wear, syngas composition, temperature and slag properties;

- demonstration of IGCC plant with integrated $\mathrm{CO}_{2}$ capture.

\section{$\mathrm{CO}_{2}$ capture}

Analysis shows that CCS is an essential component of measures designed to reduce global $\mathrm{CO}_{2}$ emissions and help avoid the most serious impacts related to climate change. Despite a great deal of effort to develop reliable and effective capture technology, at the large-scale, CCS is not yet commercially available for power generation applications. To effectively address the high cost and energy penalty resulting from $\mathrm{CO}_{2}$ capture, many countries are pursuing large-scale demonstrations of CCS technology. According to a study commissioned by the Global CCS Institute (2010), 80 large-scale projects are currently at various stages of development around the world.

Though it is likely that CCS will be installed as new power plants are introduced, a requirement for it to be retrofitted to existing power plant is also anticipated. It would be significantly advantageous if new plants could be adapted to capture $\mathrm{CO}_{2}$ at a future date, i.e. be CCS ready. Movement in this direction is already under way. France passed new legislation in 2009 requiring any new coal power station project to be CCS ready and be accompanied by a full-scale CCS demonstration programme. Also in 2009, "A Framework for the Development of Clean Coal" prohibited the construction of new coal-fired power stations without the demonstration of CCS in England and Wales, setting out plans for the long-term transition to clean coal. Ministers announced a similar approach in Scotland. The Australian government was also recently elected, in part, on a platform proposing that approval of new coal-fired power stations should be contingent on their capability of retrofit with CCS technologies.

\section{$\mathrm{CO}_{2}$ capture using oxy-fuel technology}

Oxy-fuel technology is being developed for $\mathrm{CO}_{2}$ capture. In principle, it can be applied to both PC combustion and CFBC units.

The nitrogen that comprises almost $80 \%$ by volume of the air, which aids combustion in both PC and CFBC boilers, dilutes the $\mathrm{CO}_{2}$ concentration in the flue gas. The stripping of $\mathrm{CO}_{2}$ from such dilute mixtures using amines is expensive. For oxy-fuel combustion, a combination of oxygen typically of at least $95 \%$ purity - and recycled flue gas is used for combustion of the coal. By recycling the flue gas, a gas consisting mainly of $\mathrm{CO}_{2}$ and water vapour is generated. A concentrated stream of $\mathrm{CO}_{2}$ is then produced that is ready for capture by condensing the water vapour. The recycled flue gas both controls the flame temperature in the boiler and compensates 
for the missing nitrogen, thereby ensuring that there is enough gas to carry the heat through the boiler (Figure 4).

Figure 4 Schematic of oxy-fuel technology

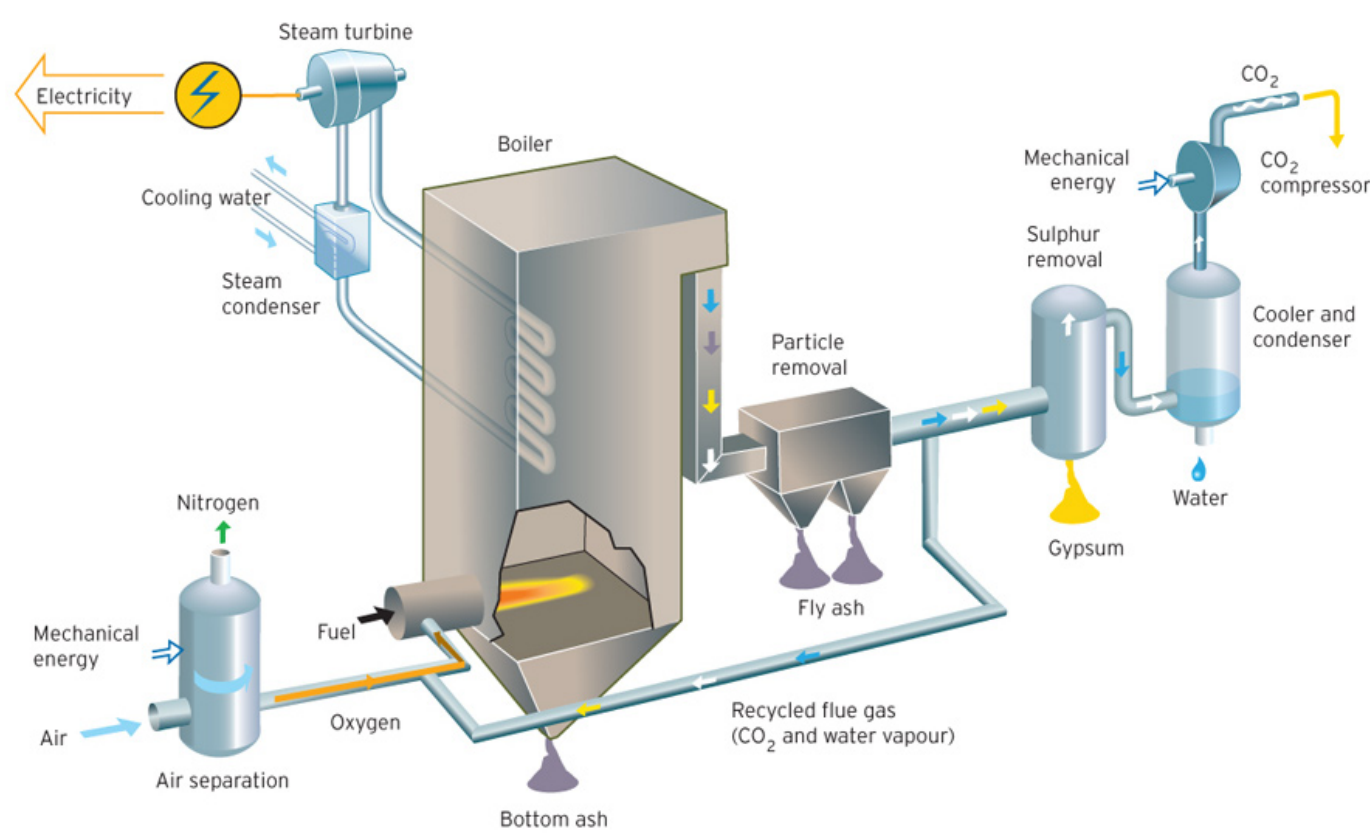

Source: Vattenfall.

The characteristics of oxy-fuel combustion with recycled flue gas differ from air combustion in a number of aspects, including:

- The high proportions of $\mathrm{CO}_{2}$ and water vapour in the furnace gases result in higher gas emissivity. To attain a similar adiabatic flame temperature and similar radiative heat transfer, the oxygen passing through the burner is typically around $30 \%$ by volume, requiring about $60 \%$ of the flue gases to be recycled for boilers running on hard coals. These figures, however, change somewhat with coal composition, and will be different depending on moisture or ash content in the coal.

- The need to supply high-purity oxygen results in a large efficiency penalty, which will be offset only as air separation technologies become more efficient. Some efficiency gains are possible with cycle designs that allow recuperation of exhaust or other low-grade heat.

\section{R\&D needs for development of oxy-fuel technology}

Oxy-fuel technology is currently being developed by a number of utilities and other project proponents. The major and immediate technical and scientific issues that need to be addressed (Kather, 2008) are:

- Identification of optimum oxygen excess and oxygen fraction;

- Burn-out behaviour of coals in atmospheres consisting of $\mathrm{CO}_{2}, \mathrm{H}_{2} \mathrm{O}$ and $\mathrm{O}_{2}$;

- Formation mechanisms of pollutants as $\mathrm{NO}_{\mathrm{x}}, \mathrm{SO}_{2}$ and $\mathrm{CO}$;

- Reliable mixture of oxygen with recycled flue gas;

- Effect of flue gas composition on heat transfer, especially by radiation; 
- Potential for low temperature flue gas heat utilisation at boiler exit to improve overall efficiency;

- Optimum temperature level for flue gas recirculation;

- Fouling and corrosion in an oxy-fuel environment; AND

- Minimisation of auxiliary power by integration of key elements.

It must be noted, however, that considerable progress has been made in the development of oxy-fuel technology (Davidson and Santos, 2010). As a result, the process is technically viable, reasonably well understood, and has been demonstrated at pilot scale. It is also being demonstrated at large scale (30 MWth or higher) and most of the individual components are in commercial operation at the required scale.

\section{Barriers to oxy-fuel development}

Though the major barriers appear to be technical in nature, a number of major projects have been undertaken or are proposed (Table 3). Experience in the construction and operation of the projects will provide invaluable information, while addressing outstanding issues. Though many of the projects are relatively small and will not initially deploy CCS, the FutureGen 2.0 project may stimulate interest in larger-scale demonstration.

Table 3 Pilot and demonstration projects on oxy-fuel technology (with coal)

\begin{tabular}{|c|c|c|c|c|c|}
\hline Project & Location & MWth & Start up & Boiler type & Main fuel \\
\hline Jupiter & US & 15 & 2007 & $\begin{array}{l}\text { Industrial } \\
\text { No flue gas } \\
\text { recirculation }\end{array}$ & $\begin{array}{l}\text { Natural gas } \\
\text { Coal }\end{array}$ \\
\hline B\&W & US & 30 & 2007 & PC & $\begin{array}{l}\text { Bituminous coal } \\
\text { Sub-bituminous } \\
\text { coal } \\
\text { lignite }\end{array}$ \\
\hline Vattenfall & Germany & 30 & 2008 & PC & Lignite \\
\hline $\begin{array}{l}\text { OxyCoal } 2 \\
\text { [burner } \\
\text { demonstration] }\end{array}$ & UK & 40 & 2009 & PC & Coal \\
\hline Pearl plant & US & 66 & 2009 & PC & Bituminous coal \\
\hline Ciuden - PC & Spain & 20 & 2011 & PC & $\begin{array}{l}\text { Anthracite } \\
\text { Petroleum coke }\end{array}$ \\
\hline Ciuden - CFBC & Spain & 30 & 2011 & CFB & $\begin{array}{l}\text { Anthracite } \\
\text { Petroleum coke }\end{array}$ \\
\hline Callide & Australia & 90 & 2011 & PC & Bituminous coal \\
\hline Jamestown & US & 150 & 2013 & CFB & Bituminous coal \\
\hline Vattenfall & Germany & 250 & 2015 & PC & Lignite \\
\hline FutureGen 2.0 & US & $\sim 600$ & 2016 & PC & Coal \\
\hline Youngdong & Korea & $\sim 300$ & 2016 & PC & Bituminous coal \\
\hline
\end{tabular}

It is important that the pilot and demonstration projects receive regulatory and financial support to demonstrate the effectiveness of the technology for both hard coals and lignites. 


\section{$\mathrm{CO}_{2}$ capture from $P C$ and $C F B C$ plants}

An alternative to deploying oxy-fuel technology for PC or CFBC plants would be to use chemical solvents to capture the $\mathrm{CO}_{2}$. Continuing $\mathrm{R} \& \mathrm{D}$ needs for capture using chemical solvents include:

- Development of better solvents to resolve issues of corrosion and reagent loss;

- Reduction of detrimental effects on efficiency and generation cost; and

- Development of membrane contactors and other absorption systems.

Large-scale, integrated demonstration of CCS is required, including demonstrations of both newly constructed plant and retrofit. A number of projects have emerged and are being developed (Global CCS Institute, 2011).

There are more than $1500 \mathrm{GWe}$ of existing coal-fired capacity worldwide, mostly PC units. At the current state of technology development, $\mathrm{PC}$ or CFBC units retrofitted with $\mathrm{CO}_{2}$ capture will result in a loss of efficiency of up to 10 percentage-points. In fact, this efficiency penalty has reduced significantly as a result of concerted effort over the past five years. A significant part of the existing fleet is likely to be unsuitable for $\mathrm{CO}_{2}$ capture retrofit either because the efficiency of the plant is too low and/or its capacity too small. High efficiency is likely to be preferred for $\mathrm{CO}_{2}$ capture retrofit. If $40 \%$ efficiency were to be considered a minimum for retrofit with $\mathrm{CO}_{2}$ capture, less than $10 \%$ of the current world coal-fired capacity would qualify. Even then, other factors would need to be explored to assess a plant's suitability for retrofit.

As CCS becomes more widely deployed, PC technology will also be moving to higher pressure and temperature steam conditions, with plants targeting steam temperatures in the region of $700^{\circ} \mathrm{C}$ and pressures to 375 bar. The energy penalty associated with CCS should become lower as experience with the technology increases and more energy efficient capture processes are developed. When subsequently combined with $\mathrm{CO}_{2}$ capture, power generation efficiencies with capture will approach those of current non-capture plants. The cost of capture is also anticipated to reduce with experience and further development.

Inevitably, $\mathrm{CO}_{2}$ capture increases the complexity of the power generation process, whether it is added to a PC or CFBC plant. The operability and flexibility of plants with capture need to be assessed, in particular the dynamic performance during start-up, shut-down and load-changing conditions.

\section{$\mathrm{CO}_{2}$ capture from IGCC plants}

A number of factors need addressing if an IGCC plant is to be made CCS ready. These factors vary according to the type of gasifier used, e.g. whether it is oxygen or air-blown, or dry or slurry fed. Each plant design will require a different retrofit strategy because of the multiple options available (Kubek et al., 2007), each of which has a different impact (Table 4).

For IGCC with $\mathrm{CO}_{2}$ capture, the dust-free syngas would be sent to a shift reactor to produce $\mathrm{CO}_{2}$ and additional hydrogen. The $\mathrm{CO}_{2}$ would be separated and the hydrogen-rich syngas burnt in the gas turbine. Interestingly, the $\mathrm{CO}_{2}$ capture could be combined with an acid gas removal plant that would also remove sulphur gases. Sulphur gases could alternatively be removed before the shift reactor. As the shifted fuel gas is at elevated pressure and the $\mathrm{CO}_{2}$ is in higher concentration (and therefore has a higher partial pressure), it can be relatively easily separated by physical means, keeping cost and efficiency penalties lower compared to chemical scrubbing systems for PCbased plants. 
Table 4 Impact of capture retrofit on IGCC plant design

\begin{tabular}{|c|c|c|}
\hline Standard provisions & Moderate provisions & Extensive provisions \\
\hline $\begin{array}{l}\text { Space for additional equipment, } \\
\text { balance of plant, and site access } \\
\text { at later date. }\end{array}$ & $\begin{array}{l}\text { Additional air separation unit, } \\
\text { gasification and gas clean-up is } \\
\text { needed to fully load the gas turbines } \\
\text { when 'water shift' is added. }\end{array}$ & $\begin{array}{l}\text { Design with conversion-shift reactors, } \\
\text { oversized components, acid gas } \\
\text { removal absorber sized for shifted } \\
\text { syngas, but no } \mathrm{CO}_{2} \text { absorber and } \\
\text { compressor. }\end{array}$ \\
\hline \multirow[t]{2}{*}{$\begin{array}{l}\text { Net power capacity, efficiency, } \\
\text { and cost penalty upon conversion } \\
\text { to } \mathrm{CO}_{2} \text { capture. }\end{array}$} & $\begin{array}{l}\text { Above additional capacity can be used } \\
\text { in pre-capture phase for supplemental } \\
\text { firing or co-production. }\end{array}$ & $\begin{array}{l}\text { No need for major shutdown to } \\
\text { complete conversion to } \mathrm{CO}_{2} \text { capture. }\end{array}$ \\
\hline & $\begin{array}{l}\text { Allows full gas turbine output with } \\
\text { hydrogen when } \mathrm{CO}_{2} \text { capture is added. } \\
\text { Mitigates the cost and efficiency } \\
\text { penalty. }\end{array}$ & \\
\hline
\end{tabular}

Capture may also be accomplished by using pressure-swing adsorption or gas-separation membranes. Hydrogen production using coal gasification is an established technology for ammonia manufacture, where $\mathrm{CO}_{2} /$ hydrogen separation by physical solvent scrubbing is normal practice. There are prospects in the long term for reducing the energy penalty for $\mathrm{CO}_{2}$ capture in IGCC to perhaps around four percentage-points by use of innovative systems, such as membrane reformer reactors; where reforming, shift and $\mathrm{CO}_{2}$ capture would be carried out in a single reactor.

IGCC-CCS demonstration plants are emerging with funding sources from the public and private sectors. NUON, a part of the Vattenfall Group, has constructed a $\mathrm{CO}_{2}$ capture pilot plant at its $253 \mathrm{MWe}$ IGCC at Buggenum (the Netherlands); the knowledge and experience gained in the pilot will support further development and implementation at future demonstration plants and commercial concepts. In 2010, Tampa Electric Corporation announced plans to partner with RTI International to construct a pilot project to demonstrate technology to capture and sequester $\mathrm{CO}_{2}$ from TECO's Polk County IGCC power station. RTI will design, construct and operate the pilot plant that will capture $\mathrm{CO}_{2}$ from a $30 \%$-side stream to demonstrate the technology. The completion of construction of this pilot plant is planned for 2013 .

\section{CCS Ready}

Building on earlier work, a workshop was organised jointly by the IEA, the CSLF and the Global CCS Institute to define what is meant by "CCS ready" (IEA, 2010c). Held in Ottawa, Canada in March 2010 and attended by experts representing government, industry and NGOs, an ad hoc CCS-Ready working group was assembled to define and to draft guidelines for CCS ready. Their findings were as follows:

\section{Definition of CCS ready (CCSR)}

A CCSR facility is a large-scale industrial or power source of $\mathrm{CO}_{2}$, which could, and is intended to, be retrofitted with CCS technology when the necessary regulatory and economic drivers are in place. The aim of building new facilities or modifying existing facilities to be CCSR is to reduce the risk of carbon emission lock-in or of being unable to fully utilise the facilities without CCS (stranded assets) in the future. CCSR is not a $\mathrm{CO}_{2}$ mitigation option, but a way to facilitate $\mathrm{CO}_{2}$ mitigation in the future. CCSR ceases to be applicable in jurisdictions where the necessary drivers are already in place, or once they come in place. 


\section{Essential requirements of a CCSR facility}

The essential requirements represent the minimum criteria that should be met before a facility can be considered CCSR. The project developer should:

- Identify one or more potential storage areas, which have been appropriately assessed and found suitable for safe geological storage of projected full lifetime volumes and rates of captured $\mathrm{CO}_{2}$;

- Identify realistic pipeline or other route(s) to storage of $\mathrm{CO}_{2}$;

- Carry out a site-specific study in sufficient engineering detail to ensure the facility is technically capable of being fully retrofitted for $\mathrm{CO}_{2}$ capture, using one or more proven or suitable choices of technology, for which performance can be reliably estimated;

- Demonstrate that retrofitted capture equipment can be connected to the existing equipment effectively without an excessive outage period, and that sufficient space will be available to construct and safely operate additional capture and compression facilities;

- Identify other known factors, including any additional water requirements that could prevent installation and operation of $\mathrm{CO}_{2}$ capture, transport and storage, and identify credible ways in which they could be overcome;

- Estimate the likely costs of retrofitting capture, transport and storage.

- Engage in appropriate public engagement and consideration of health, safety and environmental issues;

- Review CCSR status and report on it periodically.

\section{Definition application}

These essential requirements represent the minimum criteria that should be met before a facility can be considered CCSR. However, a degree of flexibility in the way jurisdictions apply the definition will be required to respond to region- and site-specific issues, and to take account of the rapidly changing technology, policy and regulatory background to CCS and CCSR, both globally and locally. More specific or stringent requirements could be appropriate, for instance, in jurisdictions where the CCSR regulator is working on the assumption that CCS will need to be retrofitted to a particular facility within a defined time frame. Further information on CCSR in a recent IEA publication, "Carbon Capture and Storage: Model Regulatory Framework" (IEA, 2010d). 


\section{Developments in Coal Treatment}

It is accepted that coal treatment can bring considerable environmental benefits, including reduced emissions of $\mathrm{SO}_{2}, \mathrm{NO}_{x}$, particulates and $\mathrm{CO}_{2}$, through the supply of clean coal of consistent quality to downstream utilisation processes.

Coals are extremely heterogeneous, varying widely in their content and properties from country to country, mine to mine, and even from seam to seam. The principle impurities are ash-forming minerals and sulphur. Some are interspersed through the coal seam, some are introduced by the mining process, and some - principally organic sulphur, nitrogen and some mineral salts - are bound organically to the coal.

These impurities affect the properties of the coal and the combustion process, including the nature of the flue gas emissions and the combustion residues. The coal beneficiation or preparation process, which also often goes by the terms coal cleaning or coal washing, is aimed at separating and removing the impurities to the extent possible and economically feasible. Coal beneficiation aims to separate the coal from the impurities mainly by exploiting differences in density. Physical coal preparation processes target inorganic impurities and do not remove those organically bound to the coal. Sulphur is a prime target to reduce sulphur dioxide emissions following combustion. It is present both as an inorganic component (pyrite particles), and organically bound.

Coal beneficiation is in principle possible for most bituminous coals and anthracite, which account for about two-thirds of worldwide coal production. About one-third of this potential amount is presently washed. Among the largest producing countries, most coals from the United States, Australia and South Africa are already washed/cleaned close to the economic limit; while in China, India, Russia, Poland and some smaller producing countries there is scope for the increased use of coal beneficiation (Ghosh 2007).

Lignites and sub-bituminous coals pose a different set of problems. While they are often low in ash and sulphur, they tend to contain a high percentage of moisture, ranging from some $20 \%$ to $60 \%$. This will cause a range of problems in a coal-fired boiler, requiring more energy and causing higher mill, coal pipe and burner maintenance requirements. Beneficiation techniques involve drying these coals as efficiently and cost-effectively as possible.

A further issue with low-rank coal is spontaneous combustion. Susceptibility to this increases with storage time and is inversely related to the rank of the coal and to its moisture content. Consequently, drying the coal is best done immediately prior to combustion.

\section{Coal beneficiation}

A number of countries, notably India, China, Czech Republic, Poland, South Africa, Romania and Turkey use high-ash coals for power generation (Figure 5).

During the mining operation, ash and other extraneous matter are also extracted with the coal. Coal beneficiation is a process that improves the quality of coal by reducing the extraneous matter or reducing the associated ash, or both. The two basic processes of beneficiation (Satyamurty, 2007) are: 
- dry de-shaling: non-coal matter or shaly coal is removed using no liquid media; and

- wet process: coal is crushed and put in a liquid media (usually water) of adjustable specific gravity to separate the lighter coal (with low-ash content) from heavier coal (with high ash content). The rejects from the wet process also contain carbonaceous matter.

Some of the major benefits of coal beneficiation include:

- Costs are reduced by transporting rock over shorter distances;

- Savings are made in the capital and operating costs of the power plant, particularly the boiler, coal handling and ash handling systems;

- The cost of power generation may also be reduced if the washed coal increases the plant load factor and the washery rejects are utilised efficiently in fluidised bed boilers.

\section{Need for pricing incentives for coal beneficiation}

At present, coal pricing policies do not always favour coal beneficiation. If prices were to reflect coal quality and the consequences and costs of pollution, it is likely that this process would be utilised more widely. If these 'benefits' are not reflected in the price, the coal producer or supplier has less incentive to clean the coal.

The situation in India is a point in case. Most of the coal that India uses for power generation is not cleaned (Satyamurthy, 2007). Studies show that even screening of the rocks that are often included in the coal would significantly decrease the costs of coal transportation. One of the barriers to washing is the prevailing practice in India of pricing coal on grades based on useful heat value with wide bands, instead of a fully variable system based on the more precise international practice of using its gross or higher heating value (HHV). If the price of coal is made fully variable, based on its heat content measured in HHV, then the producer would be encouraged to undertake coal beneficiation (Satyamurthy, 2007). Coal India, which is the major supplier of coal to power stations in India, currently washes less than $20 \%$ of its coal before supplying it to power stations. By 2012 , their target is to wash $70 \%$ of the coal and to wash the coal produced from all new coal mines (Coal India, 2008). Though it is pursuing plans to install 20 further washeries, this clearly presents a major challenge for Coal India. In addition, the Government of India has mandated that coal shipped to power plants more than $1000 \mathrm{~km}$ from the mine should be washed so that ash content is limited to $32 \% \pm 2 \%$. As a result, it is projected that coal washing will rise from 55 million tons in 2007 to 163 million tons by 2012 (Deshmukh, 2008).

\section{$R \& D$ needs for coal beneficiation}

It is important to develop new technologies to make significant reductions in ash content through coal beneficiation. Increasing the yield of low-ash coal and reducing the consumption of water are the two major challenges to be overcome by the wet process for coal beneficiation.

\section{Developments in coal drying}

Low-rank coals containing high-moisture (30\% to $70 \%$ on as-received weight basis) represent a significant resource worldwide. An estimated $45 \%$ of the world's coal reserves are lignites (brown coal). These are inexpensive, low in ash and sulphur reserves, but have a high-moisture content of up to $65 \%$ on an as-received basis. Brown coal represents an important source of power 
generation in several countries, including Australia, Germany, Greece, Poland, Russia, Turkey and the United States.

Indicative ranges of moisture content, ash content and calorific values of lignites for the major countries using high-ash and/or high-moisture coals are shown in Figure 5.

Page | 30 Figure 5 High-ash and/or high-moisture containing coals often termed as lignites

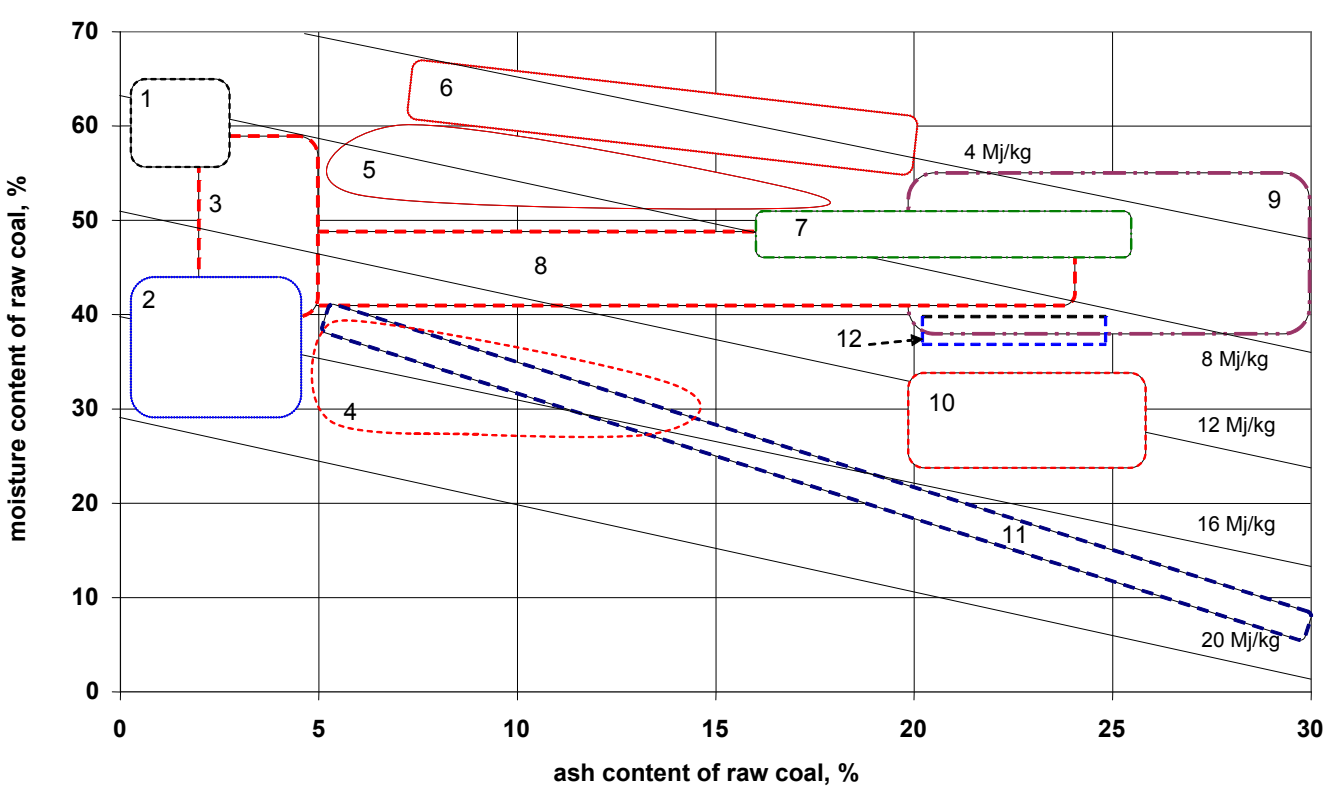

Note: their location, and calorific values (LHV, MJ/kg); country labels as follows:

1: Australia; 2: Indonesia; 3: India; 4: United States (Texas, North Dakota); 5: Germany; 6: Greece; 7: Spain; 8: Poland; 9: Czech Republic; 10: China; 11: Turkey; 12: Romania.

\section{The need for coal drying}

Coal pre-drying is an important step towards improving the efficiency of both existing and new power plants using high-moisture coals. In general the efficiency of a unit using coal drops by about 4 percentage-points and 9 percentage-points when coal moisture content increases from $10 \%$ to $40 \%$ and $60 \%$ respectively. Apart from efficiency reduction, high moisture increases coalhandling feed rate, demands more auxiliary power for coal-handling systems and pulverisers, and leads to higher plant operating and maintenance costs.

Unfortunately, drying high-moisture coals increases the risk of spontaneous combustion (due to their high oxygen content, they are usually more reactive than hard coals). Thus, in most power plants using high-moisture coals, drying has to be carried out immediately prior to combustion, i.e. in and around the mill, by recirculating some of the flue gases from the upper part of the boiler. This requires a boiler substantially larger to cope with the water vapour; the higher the moisture content, the larger the boiler (Figure 6). To handle the additional volume of water vapour, the fan power requirement would be higher, which results in higher auxiliary power requirements and reduced efficiency. If high-moisture coal could be pre-dried, the boiler size could be smaller; and if low-grade or waste heat could be used for drying, the boiler efficiency could be higher as well. 


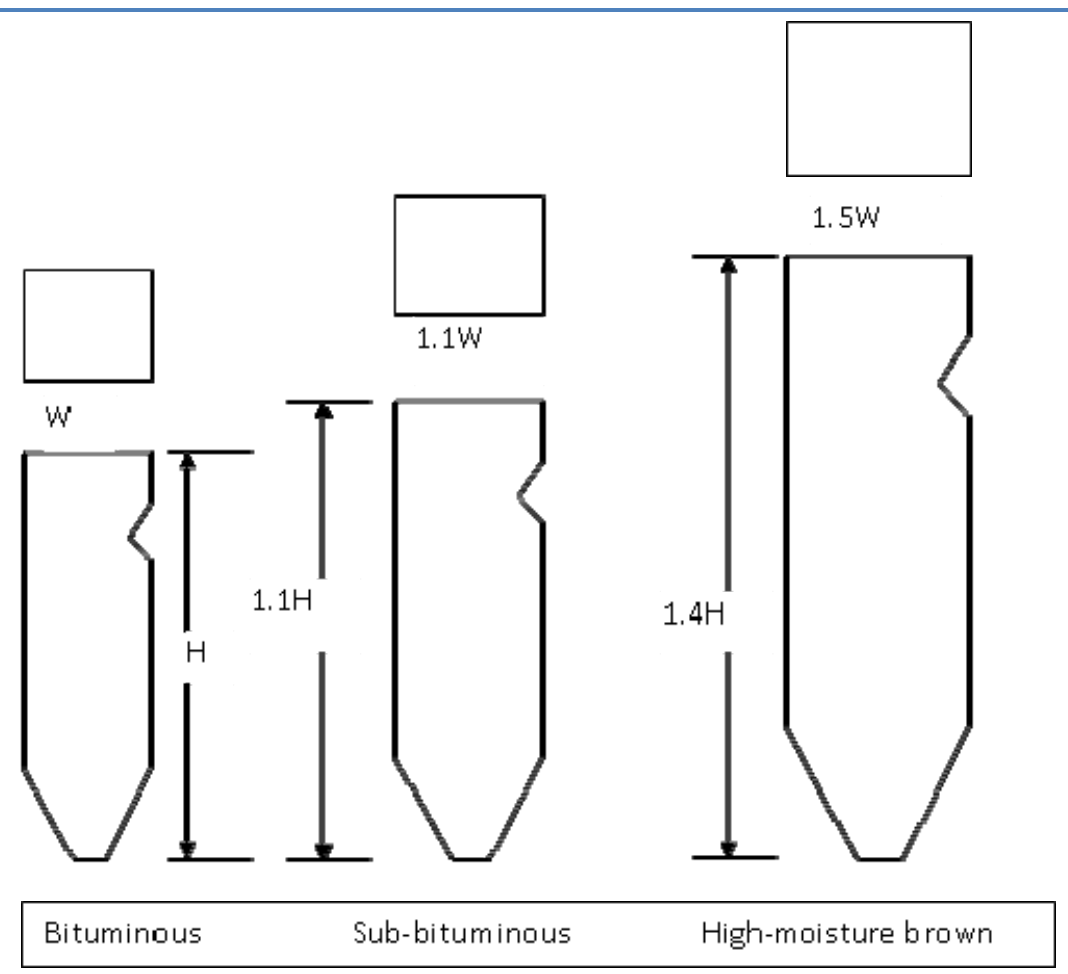

Source: St Baker and Juniper, 1982.

When the net energy requirement for pre-drying is low relative to the energy required for drying in a conventional plant, a higher thermal efficiency is achieved. This results from using drying technologies that utilise lower grade energy and recover the exhaust heat from the dryer effluent and/or remove the water without evaporation, hence avoiding the extensive loss of latent heat in evaporation.

Global emissions from coal-based power and heat production are around 7.5 billion $\mathrm{tCO}_{2} / \mathrm{yr}$. It has been estimated that, by improving the average efficiency of the operating coal fleet from its 2004 level to about $42 \%$ (LHV, net), $\mathrm{CO}_{2}$ emissions would be reduced by between 1.35 and 1.7 billion $\mathrm{tCO}_{2} /$ year, i.e. equivalent to the total $\mathrm{CO}_{2}$ emissions of Russia in 2008. Intensive predrying of high-moisture coals could make a significant contribution, reducing emissions by as much as 0.3 billion tonnes $\mathrm{CO}_{2}$ /year. For some countries, such as Australia, Germany, Indonesia and Russia, the reduction as a proportion of the national $\mathrm{CO}_{2}$ emissions from power production could be substantial. 
- Raises overall unit efficiency by increasing boiler efficiency thereby reducing $\mathrm{CO}_{2}$ emissions

- Lowers boiler size and unit auxiliary power consumption by reducing the flow rates of coal and flue gas.

- Reduces the flue gas flow rate, due to increased boiler efficiency. Reducing this flow rate also facilitates additional $\mathrm{SO}_{2}$ capture by a scrubber for coals containing high sulphur.

- Reduces unit $\mathrm{NO}_{x}$ emissions by increasing coal's heating value and reducing the flow rates of coal and primary air to pulverisers.

- Increases mercury oxidation during the combustion process as a result of using drier coal. This oxidised mercury, which is water-soluble, can be removed by the wet-lime spray towers.

- Eliminates the need for premium alternative heat sources (for example, high pressure steam or additional fuel) through the use of low-grade or waste heat.

In the United States, 35 units, with a capacity totalling $15 \mathrm{GW}$, operate using lignites with moisture contents up to $40 \%$; another $100 \mathrm{GW}$ facilities run on sub-bituminous Powder River Basin coal with moderate levels of moisture. Over the next two decades, another $100 \mathrm{GW}$ capacity should be added that would use high-moisture lignites. If the existing $15 \mathrm{GW}$ capacity is fitted with pre-drying to reduce coal moisture by 10 percentage-points, the $\mathrm{CO}_{2}$ emissions could be reduced by over 10 million tonnes $(\mathrm{Mt})$ annually; with the added benefits of reducing emissions of $\mathrm{NO}_{x}, \mathrm{SO}_{2}$ and mercury. Drying to a lower moisture content with low-grade heat would reduce $\mathrm{CO}_{2}$ emissions even further.

A substantial amount of R\&D work has been undertaken on drying high-moisture coals, notably in Australia, Germany, Russia and the United States. Recent work on the development of predrying processes is summarised in the following sections.

\section{Steam fluidised-bed drying}

As already discussed, high-moisture coals are prone to spontaneous combustion when dried. They should preferably be dried in the absence of oxygen - or, alternatively, at a low oxygen level at lower temperatures, i.e. less than $50^{\circ} \mathrm{C}$ - in an inert medium such as steam, which is readily available in a power station (Figure 7).

In a steam fluidised-bed dryer, raw coal is fluidised by steam, and heat is supplied through immersed tubes using high temperature steam. Usually, a temperature gradient of around $50^{\circ} \mathrm{C}$ between the heating steam and the dryer bed is preferred to ensure an optimum level of drying and drying time. This means that for drying to be accomplished at atmospheric pressure (around $100^{\circ} \mathrm{C}$ saturation temperature in the bed), the heating steam is at around 5 bar. This steam can potentially be supplied from low-pressure turbines in a coal-fired plant. Steam drying underwent extensive testing and development in Germany, and to a lesser extent Australia, between 1990 and 2002 (von Bargen, 2007). A stand-alone dryer has been demonstrated at $170 \mathrm{t} / \mathrm{hr}$ of raw coal feed in Germany. 
Figure 7 General schematic of steam fluidised-bed drying

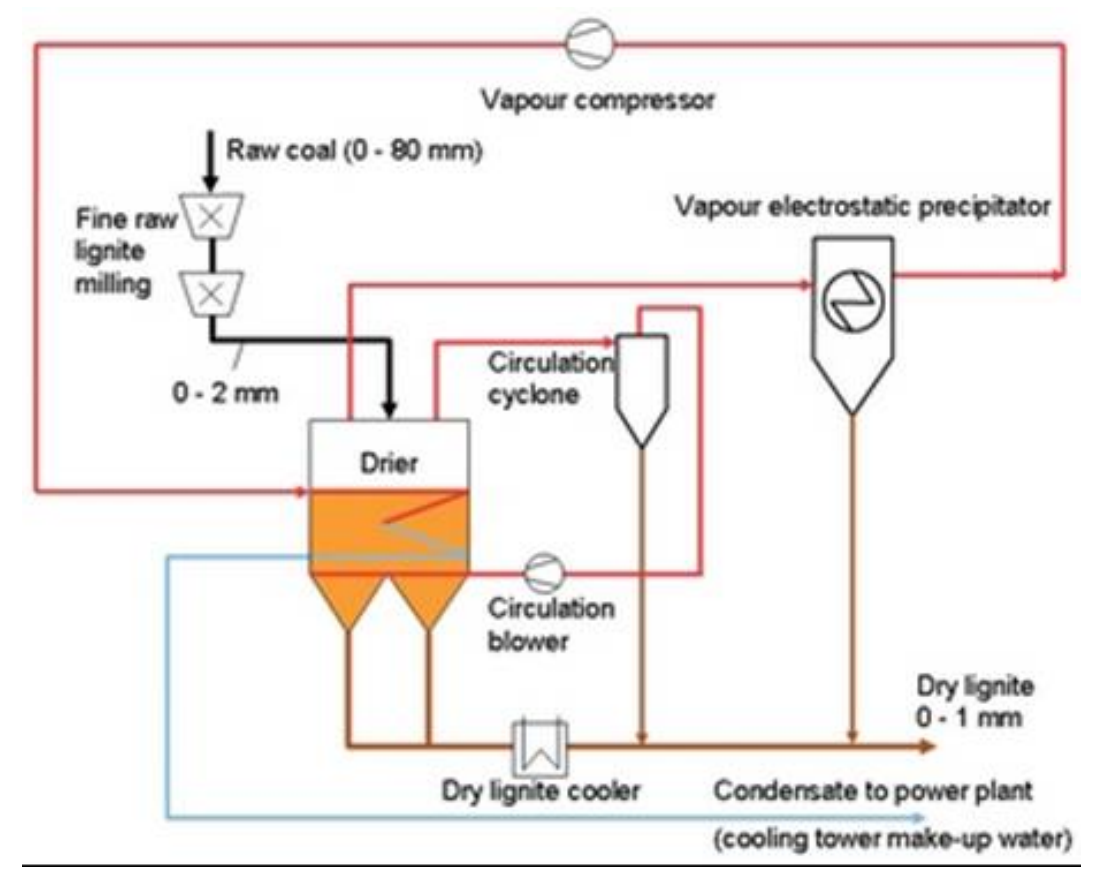

Source: RWE Power.

Variations of the process shown in Figure 7 are possible, e.g. the vapour compressor may be completely dispensed with and the vapour either released into the atmosphere or used for thermal recuperation. In such a case, the heating steam, which is in the immersed coil, could be sourced from the steam cycle of the plant.

The volume of the dryer and the level of drying that can be achieved in a steam fluidised-bed dryer depend on a number of factors, including:

- The conditions of the steam used for heating;

- The particle size of raw coal feed, which would in turn affect the drying time;

- The fluidisation velocity, which is important to ensure optimal contact between the heating steam and the particles.

\section{Steam fluidised-bed drying development work in Germany}

Process designs for lignite drying that can reduce the energy penalty are clearly desirable. RWE have developed a proprietary drying system, the "WTA process" whereby raw coal (up to $80 \mathrm{~mm}$ ) is milled to a fine grain $(0 \mathrm{~mm}$ to $2 \mathrm{~mm}$ ), which is then dried in a steam fluidised bed. Use of fine grain coal for drying reduces the size and, therefore, the cost of the dryer. It also reduces the steam required to maintain fluidisation and requires slightly lower steam conditions than would be the case for drying coarser coal. Sixty-six percent of the resulting dried coal is less than $90 \mu \mathrm{m}$ particle size, and less than $9 \%$ greater than $1 \mathrm{~mm}$ particle size (Klutz et al., 2006).

RWE is undertaking a large-scale demonstration of the WTA process at one of their coal-fired power station units, Niederaussem K. Results indicate that the unit achieves a much better efficiency than previous lignite units because of the efficiency maximising measures of the plant's 'BoA' or optimised efficiency technology system (Figure 8). 
Figure 8 WTA lignite drying in comparison with conventional system

BoA concept

Integrated milldrying

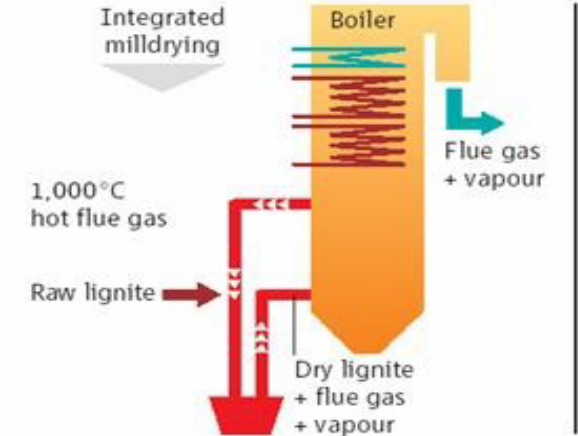

Energetic disadvantages:

- drying at very high exergy level

- no use made of vapour energy

Source: RWE Power.
BoA concept with predried lignite

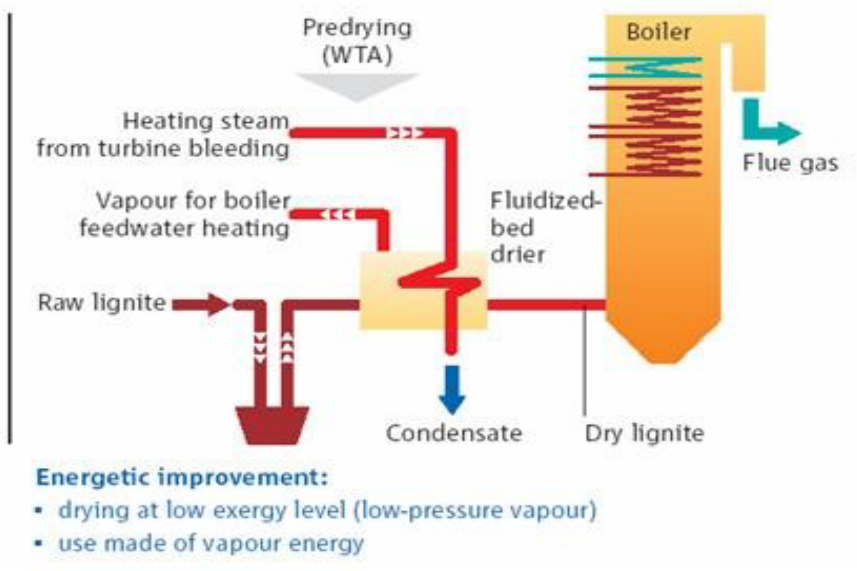

The Niederaussem plant, where $25 \%$ of Unit K's input fuel is being treated, is designed to reduce the coal moisture content from about $50 \%$ to between $10 \%$ and $18 \%$, prior to feeding into the mills (Figure 9). Energy is saved by feeding only low-grade heat $\left(120^{\circ} \mathrm{C}\right)$, in the form of lowpressure steam, to fluidise and directly dry the coal, and by recovering much of the latent heat from the liberated steam and cooled steam from fluidisation in a feedwater heater.

When operating, this process should increase the efficiency of Niederaussem $\mathrm{K}$ by around one percentage-point. When applied to the full coal flow to the plant, it would be expected to raise efficiency by around four percentage-points. This would raise the efficiency of the overall plant from its existing design efficiency of $43.2 \%$ (LHV, net), already world class for a lignite-fired power station, to $47.2 \%$ (LHV, net). Subject to satisfactory performance, the drying plant would be scaled-up to fit a full-scale coal-fired unit. It has been estimated that the full coal pre-drying plant would result in an incremental investment cost of EUR 70/kW.

Figure 9 WTA demonstration lignite drying plant on Niederaussem K

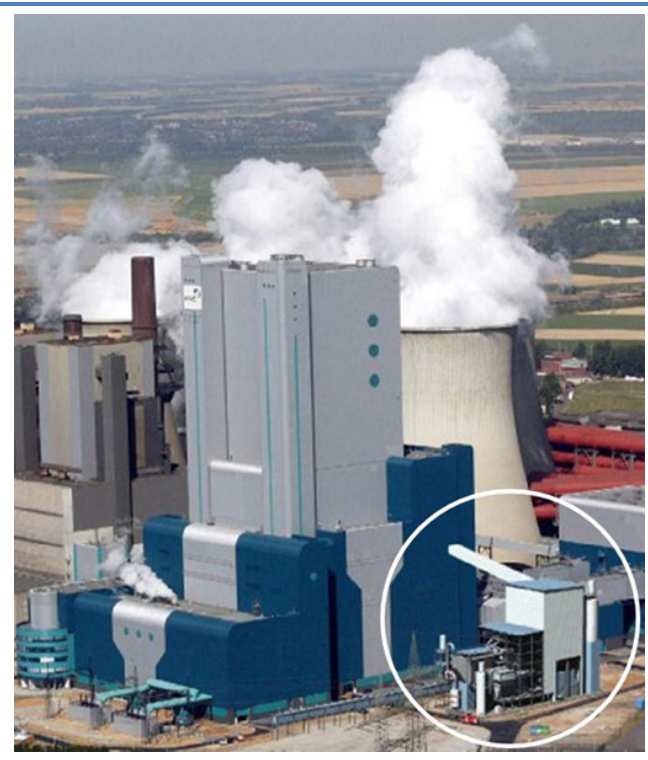


The WTA technology is also being demonstrated at the Hazelwood Power Station in Victoria, Australia (Innocenzi, 2008). A WTA drier is being retrofitted to an existing 200 MWe unit to dry $50 \%$ of the original feed of high-moisture coal, with the intention of reducing the moisture content from about $60 \%$ to $12 \%$. The dried coal would then be co-fired with $50 \%$ high-moisture coal into the boiler. If all the coal feed were to be pre-dried from its current level of $60 \%$ to $12 \%$, the resulting efficiency gain could be in the region of 4 percentage-points.

\section{Fluidised-bed drying development at Great River Energy, North Dakota}

Typically, about $45 \%$ of the fuel heat in a conventional pulverised coal-fired power plant is lost in the condenser and another 20\% exits the stack. At Great River Energy (GRE), the lignite fuel enhancement system (LFES) is being demonstrated, which uses waste heat to dry fuel before it is fed into the boiler. The process exploits this low-grade heat, which otherwise has little use (Figure 10).

Figure $10 \mathrm{~A}$ schematic of the lignite fuel enhancement system, which uses waste heat from condenser water and flue gas

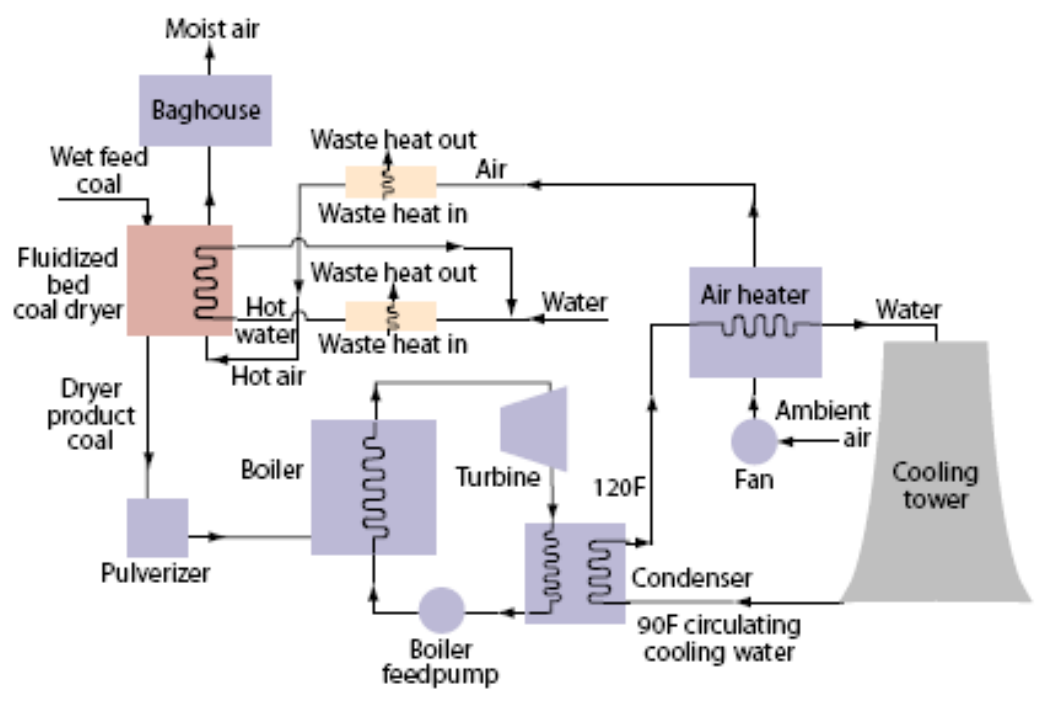

Source: Great River Energy.

In the LFES, low temperature hot air (as opposed to steam in WTA) fluidises and heats the lignite to remove moisture. The air stream is cooled and humidified as it flows upward through the fluidised bed. The amount of moisture that can be removed is limited by the drying capacity of the air stream, which is supplemented by an in-bed hot water coil.

GRE tested a number of lignites in a $2 \mathrm{t} / \mathrm{h}$ pilot-scale dryer to evaluate the drying potential of different feedstocks. Tests confirmed the viability of coal drying and provided a basis for a largerscale demonstration under the Clean Coal Power Initiative (CCPI). The CCPI-funded project progressed in phases (US DOE, 2008). In the first phase, a 115 tonnes/h prototype capable of drying up to $25 \%$ of the lignite fed to Coal Creek Station's 546 MW Unit 2 was designed, built and successfully tested. In the second phase, GRE designed four full-scale ( $135 \mathrm{t} / \mathrm{h})$ dryers able to supply $100 \%$ of Unit 2's fuel needs.

Construction of the full-scale dryer and a major overhaul of the boiler, turbine, and scrubber went ahead. The full-scale integrated four-dryer system is designed to reduce the moisture content of all coal burned at the plant by 8.5 percentage-points, from $38.5 \%$. Such a reduction 
was expected to reduce $\mathrm{NO}_{\mathrm{x}}$ emissions by $10 \%, \mathrm{SO}_{2}$ emissions by $10 \%$ to $15 \%$, mercury emissions by $15 \%$ to $20 \%$, and $\mathrm{CO}_{2}$ emissions by $2 \%$ (Gollakota and Bullinger, 2007).

\section{Mechanical thermal expression (MTE)}

The MTE process removes moisture from coal (de-waters) without evaporation, building on work undertaken at the University of Dortmund and at Diffenbacher (Strauss et al., 1999) in the late 1990s. It was demonstrated that if coal is heated to $150^{\circ} \mathrm{C}$ to $200^{\circ} \mathrm{C}$, i.e. at saturation pressure to prevent evaporation, the water in coal can be "squeezed" out by applying mechanical pressure (Figure 11). Raising the temperature makes the coal easier to deform under compression and makes the water more mobile by reducing its viscosity and surface tension.

Figure 11 Process flow diagram of the MTE Process - the press shown in horizontal orientation

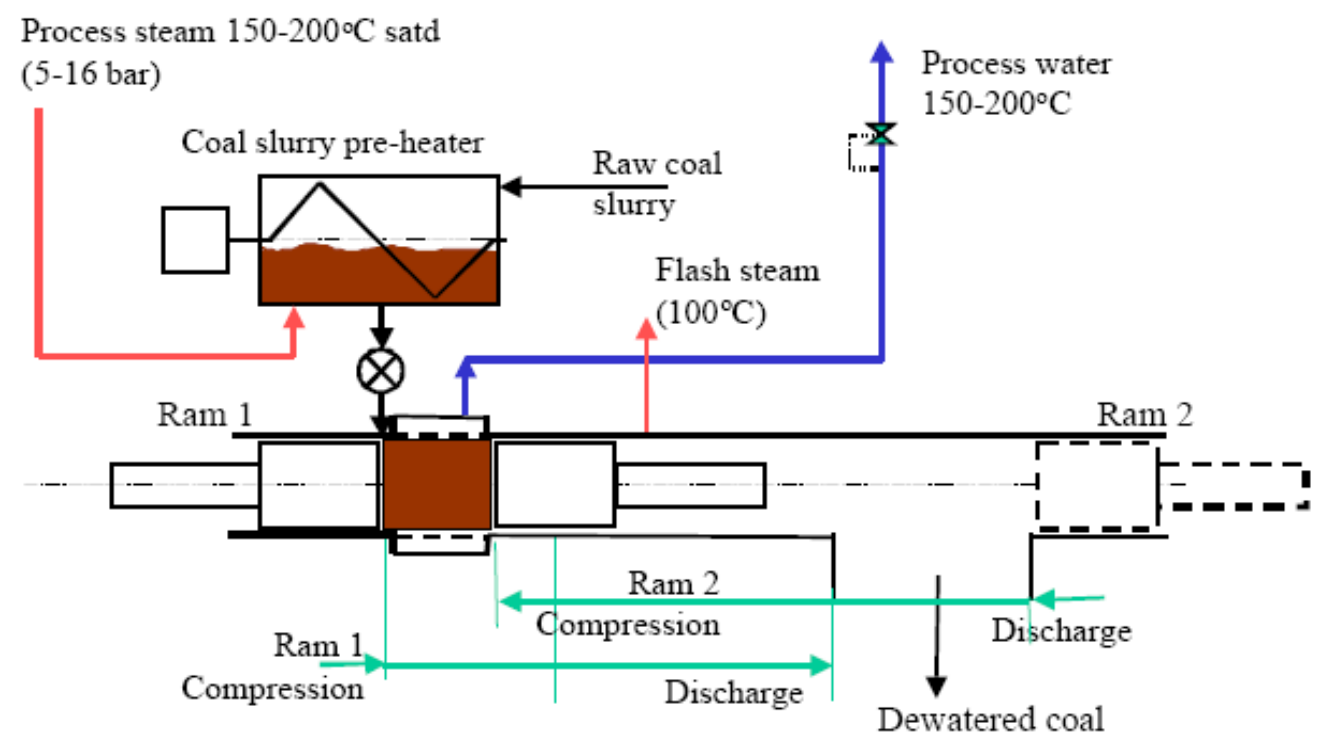

Source: Nethercote, 2008.

\section{Development work in Australia}

A substantial amount of R\&D work had been undertaken over the last two decades in Australia on MTE de-watering by the now-disbanded Cooperative Research Centre for Clean Power from Lignite. This included work at bench scale, followed by successful development work at the $1 \mathrm{t} / \mathrm{h}$ scale (Huynh et al., 2005; McIntosh and Huynh, 2005), which established the effect of process variables (pressure, temperature, coal type, duration of heating and compression) on the extent of de-watering and throughput. Numerous tests were carried out in continuous and cycling batch mode. With Victorian brown coals from the Latrobe Valley, it was demonstrated that approximately $70 \%$ of the original coal water could be removed at around $200^{\circ} \mathrm{C}$ and at moderate compression pressures of 60 to 110 bar. The throughput was found to be strongly dependent on the compression time required to de-water the coal to a specified moisture content and also depended on coal type. During the development process, components were extensively tested and proved. A 15 tonne / $\mathrm{h}$ rig was designed, constructed and operated at the Loy Yang Power (a utility) site in Victoria using funding from the Commonwealth and state governments and the Latrobe Valley generators (Nethercote, 2008). The test plant used lowgrade steam from the power station to heat the coal to approximately $200^{\circ} \mathrm{C}$; the coal was then squeezed in a hydraulic chamber to approximately 60 bar (Figure 12). 


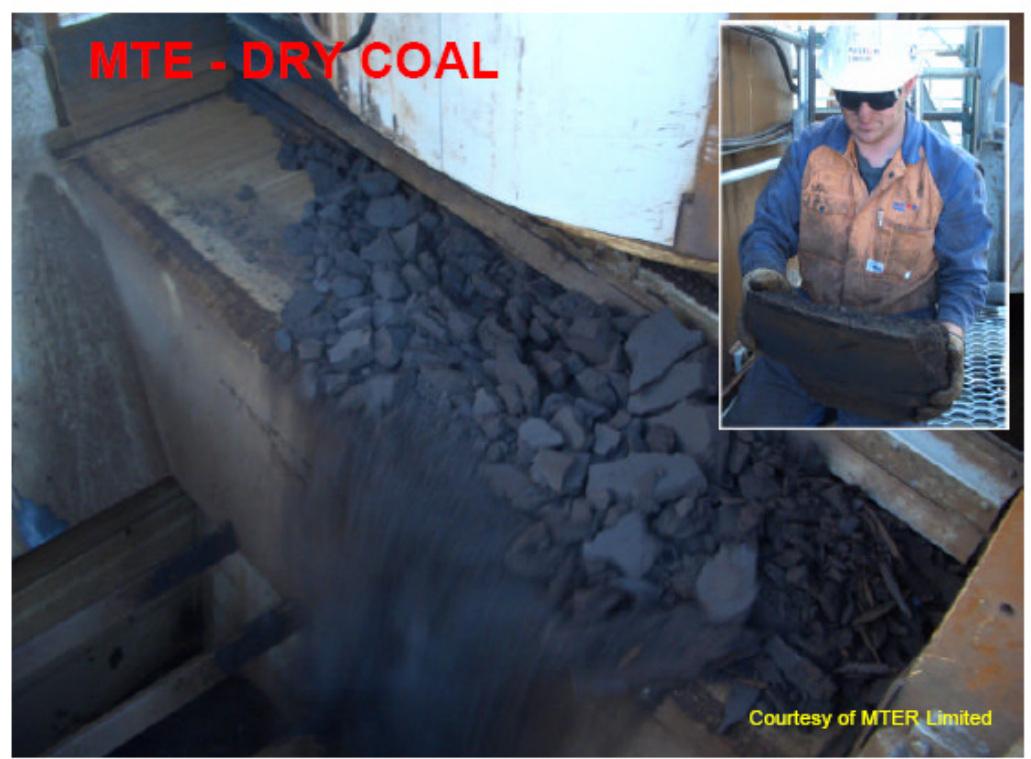

Source: Nethercote, 2008.

Advantages of the MTE process are not limited to efficiency improvement when the dried coal is burnt, but unlike other drying processes, the process also allows for the capture of the extracted water. The process of removing the moisture from the coal through squeezing may also have other benefits. Early indications are that the amount of salt left in the dried coal may be reduced after being washed out as part of the water removal operation. This would result in reduced fouling and much longer boiler operating times between cleans, particularly for salty coals. It is claimed that the use of dried coal from the MTE process (Figure 12) would reduce the physical boiler size by approximately $65 \%$, and so reduce the capital costs.

If the tests at the $15 \mathrm{t} / \mathrm{h}$ scale are successful, it will still be necessary to scale-up the process further to fit with large $(>500 \mathrm{MW})$ size boilers. There is ongoing co-operation between government and utilities to accelerate the demonstration of the MTE process at a commercial scale.

\section{$R \& D$ needs for coal drying}

Coal pre-drying technologies, once commercialised, will make the vast resource of low-rank coals of varying moisture contents much more attractive for utilisation in new units. It is likely that predrying would still be carried out close to the power stations to avoid problems relating to spontaneous combustion.

The major and immediate needs for development of drying are:

- a reliable feeding system at high pressure, $>25$ bar, for high-moisture coals; and

- drying of fine coal particles using waste heat or low-grade steam.

While both of these requirements are being addressed to varying extents, there is an urgent need to test the technologies at full-scale on a coal-fired power plant. Incentives are also required to accelerate the development and commercialisation of coal pre-drying technologies to full scale. International co-operation is also important among technology developers and utilities that use high-moisture coals. 


\section{Developments in Major Components}

This section examines the development of major components of coal-fired power systems. Apart from the section dealing with steam turbines, it should be noted that the components reviewed are only relevant to PC plant, i.e. pulveriser sub-systems and the ignition system. The

Page | 38 development of major components related to other processes, e.g. for an IGCC, is described in Chapter 1.

\section{Development in steam turbines}

The steam turbine is one of the key components in a power plant, and is one of the areas where significant improvements can be made towards plant efficiency. A continual rising trend in the efficiency of steam turbines has followed the increasing boiler capacities and the increasing number of feed water heating and steam reheat stages. The application in recent years of computational fluid dynamics has led to improvements in efficiency and these have also been significantly assisted by the following means (Watanabe et al., 2003):

- Improvement in the thermodynamic efficiency attained by increasing the temperature and pressure at which heat is added to the turbine.

- Improvement in mechanical efficiency obtained by reducing aerodynamics and leakage losses as the steam expands through the turbine. This has been achieved mainly through the development of high performance sealing, which can significantly reduce steam leakage through the gland seals and blade tip.

- Development of high-performance reaction blades, impulse blades and low-pressure blades, the point at which most of the loss occurs.

Though the results shown in Figure 13 are somewhat dated, they illustrate very clearly the trend of heat rate development (efficiency increase) through advanced turbine blade design (Schaarschmidt et al. 2005). The bases for such improvements included new blade design, as well as substantial optimisation in other turbine areas such as sealing and components that determine flow path (e.g. valves, steam inlets and outlets). The most significant achievements of this development were at two conventional lignite-fired power plants in Germany (Boxberg and Niederaussem). At Boxberg, a turbine heat rate of $7427 \mathrm{~kJ} / \mathrm{kWh}$ (kilojoules/kilowatt hours) was reached, equivalent to a turbogenerator efficiency of $48.5 \%$.

The size of steam turbines has also grown considerably during these developments. For $50 \mathrm{~Hz}$ cycles, the limit is currently around $1100 \mathrm{MWe}$ turbine size. It is important to note that, in general, the specific capital and operating costs of a power station decrease with increasing unit size, including the size of the turbines. 
Figure 13 Trend of heat rate development through advanced turbine blade design

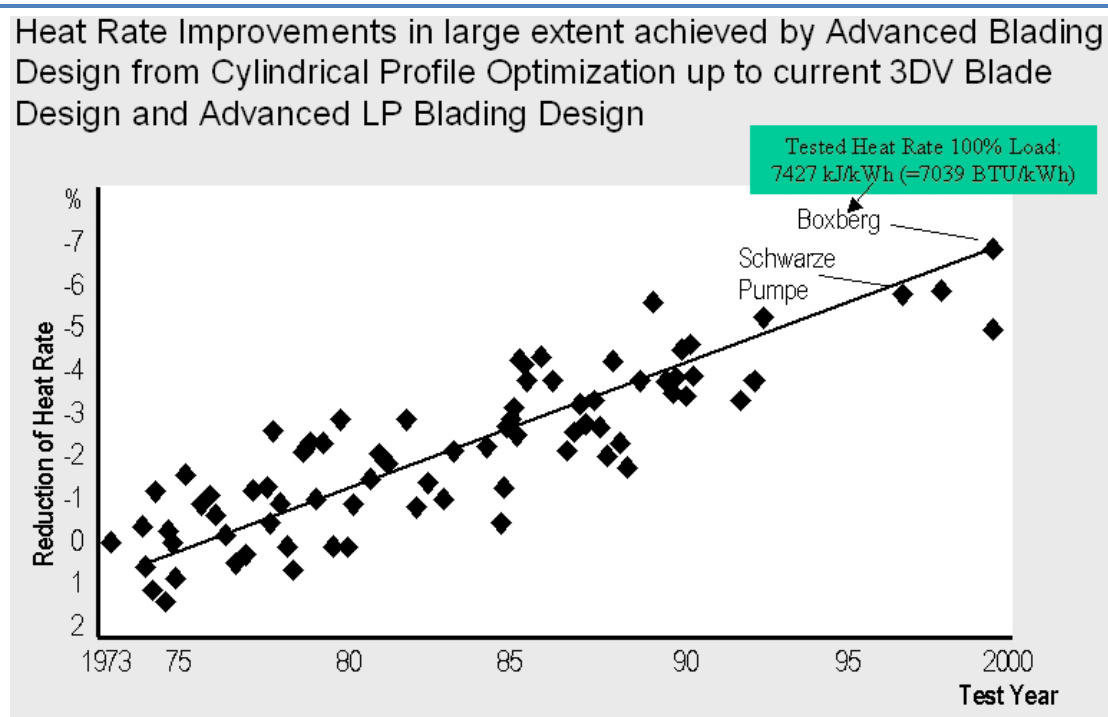

Source: Schaarschmidt et al. 2005.

\section{Dynamic classifier in pulverisers}

In most utility boilers, coal particles have one or two seconds' residence time for complete burnout. Incomplete burnout results in carbon loss and, hence, in a loss of plant efficiency. Coarse particles of coal do not burn as quickly, easily or cleanly as fine particles. As they take longer to burn, coarse particles raise a boiler's average $\mathrm{NO}_{\mathrm{x}}$ emissions and are also detrimental to the $\mathrm{NO}_{\mathrm{x}}$ control system. They result in agglomeration and deposition of slag, making the boiler vulnerable to fouling.

Pulverisers traditionally had only a static classifier to screen out coarse particles. Dynamic classifiers, however, can increase both the fineness of the particles and the capacity of the pulveriser. Retrofitting dynamic pulverisers results in a more complete burnout of the coal particles. Thus far, dynamic classifiers have been retrofitted to several power stations, notably in the United Kingdom (Sommerlad and Dugdale, 2007), Germany and China.

\section{Plasma ignition system}

In boilers, oil is typically used for the start-up and building of the load to a level of around $30 \%$. The ability to start-up using coal directly, with no or little oil support, would reduce operating costs. A plasma ignition system has been developed by China Guodian, and has reportedly been applied in several units up to $1000 \mathrm{MW}$ unit capacity. It is claimed that the plasma ignition system can handle different types of coal, i.e. low volatile, bituminous and lignites (Ren, 2008), and can be utilised in both wall-fired and corner-fired boilers. 
Improving instrumentation and control is an effective way to increase the efficiency of power plants (Nalbandian, 2004). A digital control system, with instrumentation and control systems that automatically conducts performance analyses, process monitoring and optimisation functions, can increase cycle efficiency. Advanced control technologies can analyse for optimising boiler and turbine operations at various loads, to maximise plant efficiency with fewer trips, leading to efficiency improvements of between $5 \%$ and $10 \%$ (Ferrer and Kishinevsky, 2008). The average life of a modern instrumentation and control system varies from 10 to 15 years for PC-based systems and from 15 to 20 years for proprietary-distributed control systems. The cost of upgrading an instrumentation and control system in a coal-fired plant is estimated to range from between USD 1 million to USD 6 million (Ferrer and Kishinevsky, 2008).

Digital control can also assist in tighter environmental control and lower overall costs. The volume of information acquired by a digital bus-based system and intelligent field devices can be used to optimise plant operations and maintenance activities, and avoid unplanned outages. The next technological advance to affect plant performance is believed to be wireless technology, which will reportedly have additional, positive impacts on reliability and availability (Beedie and Brownlee, 2008). 


\section{Outlook for Development}

\section{Plant efficiency improvement}

In previous sections, means of improving the efficiency of existing power plants were identified. An indication of the potential for improvement from these measures is shown in Table 5. Some of these opportunities, and the extent to which efficiency might be increased, depend on the condition of a plant. It is important to recognise that not all of these opportunities will exist in any specific plant, and that not all of the improvements expected as a result of their implementation will arise. In many cases, the degree of improvement will be site specific and will depend on the plant design and the type of coal in use.

Table 5 Summary of efficiency improvements that can be made in an existing plant

\begin{tabular}{|c|c|c|}
\hline & Action & $\begin{array}{c}\text { Typical efficiency } \\
\text { improvements, } \\
\text { percentage-point } \\
\text { (HHV) }\end{array}$ \\
\hline $\begin{array}{l}\text { Turbine and steam cycle efficiency } \\
\text { improvements }\end{array}$ & $\begin{array}{l}\text { Improved turbine blade design, retrofit of modern } \\
\text { blade design into old turbines } \\
\text { Improvement to condenser performance and } \\
\text { turbine back pressure } \\
\text { Modification to feed water cycle } \\
\text { Improvement to turbine gland sealing } \\
\text { performance }\end{array}$ & $\begin{array}{l}\text { up to } 1 \\
\text { up to } 0.5 \\
\text { up to } 2 \\
\text { up to } 0.2\end{array}$ \\
\hline Boiler improvements & $\begin{array}{l}\text { Reduction of boiler exit temperature and air } \\
\text { leakage } \\
\text { Reduction of dry flue gas losses, and auxiliary } \\
\text { power consumption } \\
\text { Upgrade of control system } \\
\text { Addition of air heater surface, if possible }\end{array}$ & $\begin{array}{l}\text { up to } 0.8 \\
\text { up to } 1.2 \\
\text { up to } 0.5 \\
\text { up to } 2.0\end{array}$ \\
\hline
\end{tabular}

Source: Boyd, 2004; AGO, 2000.

\section{Power generation efficiency}

A large number of SC and USC PC power stations are currently operating, under construction and planned. With stricter regulatory requirements, particularly relating to $\mathrm{CO}_{2}$ and mercury emissions, the share of SC and USC systems will almost certainly increase substantially over the next few years.

Projections on progress in efficiency and emissions for coal-fired power generation show steady improvement to 2020 and beyond (Figure 14) (VGB, 2008). With appropriate policy and financial support for demonstration, VGB project that the net efficiency of state-of-the art units firing hard or bituminous coals could reach 50\% LHV (or around $48 \%$ HHV) by 2015. Given progress over the past two or three years, it is rather optimistic to expect a commercial $700^{\circ} \mathrm{C} \mathrm{PC}$ combustion plant to be operating by 2015; a date beyond 2020 is perhaps more likely. Accordingly, the large scale deployment of CCS is also likely to be later than portrayed in the figure. 
Figure 14 Efficiency improvement potential of hard coal-fired plants

$\mathrm{CO}_{2}$ reduction potential of coal-fired power plants ${ }^{1)}$ by increased efficiency

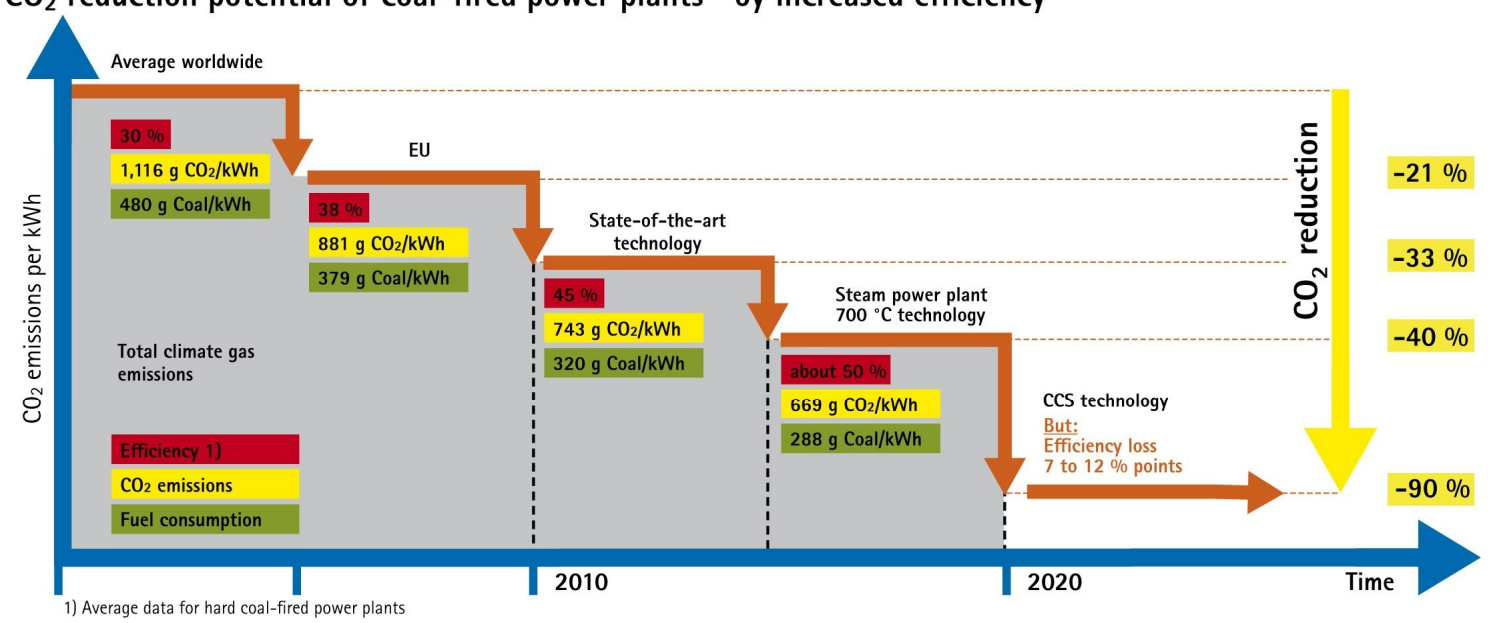

Source: VGB, 2010.

For high-moisture lignite-fired plants, these figures will be up to 5 percentage-points lower, depending on the moisture content in the coal. This figure may improve, given successful developments in efficient coal-drying technology using either waste heat or lower grade steam.

For high-ash coals, the development of a low-energy ash-cleaning technology that requires low water consumption is essential. The operating experience of newly built supercritical units in India will influence the timing and frequency of wider penetration of such units for high-ash coals.

Plans were recently put on hold for E.ON to build the world's first hard coal-fired unit (550 MWe) with a net efficiency of over $50 \%$ (LHV). The unit, due to have been located at Wilhelmshaven (Germany), would have built on the AD700 programme, with steam parameters of 350 bar and $700^{\circ} \mathrm{C}$. Measures such as heat recovery and optimisation of the low pressure turbine and preheating of feed water were also being considered in the design. Successful demonstration of the unit would have led the way for more such units for hard coals, and also possibly for lower-rank, pre-dried, low-ash and non-agglomerating coals.

Several barriers need to be addressed if IGCC is to be more widely deployed. IGCC is perceived to have operating risks that are not fully quantified. Operation and maintenance costs are less certain as fewer IGCC reference plants are operating. At its present stage of maturity, IGCC's capital costs are higher and capital availability is lower. Partly to address these concerns, and to provide a viable alternative to PC-fired units, several supplier groupings have been formed; these are offering reference IGCC plant designs on a turnkey basis with guarantees on cost, construction time, availability and efficiency.

For CFBC, it is very likely a significant market will emerge. Successful demonstration of the first supercritical CFBC unit in Lagisza (Poland) provides an important milestone.

\section{Outlook of ongoing developments in power generation}

Considerable progress has been made in the development of highly efficient SC and USC PC-fired technology. The current state-of-the-art USC plants operate at steam conditions of $600^{\circ} \mathrm{C}$ to 
$620^{\circ} \mathrm{C}$ and over 250 bar, resulting in efficiencies of $45 \%$ to $46 \%$ (LHV, net) on bituminous coals in some parts of the world. Unit sizes for such plants have reached $1100 \mathrm{MWe}$. If ongoing developments in materials succeed, efficiencies of the best PC plants can approach $50 \%$ (LHV, net) by 2020 . There is a need to execute effective policies to fast-track such technology developments towards demonstration and deployment.

At the same time, progress is being made in the development of CFBC plants. These can better utilise low-rank fuels and result in lower emissions of conventional pollutants. The first supercritical CFBC plant, at 460 MWe capacity, was commissioned at Lagisza (Poland) in 2009, and designs for even larger units exist. For CFBC, there will continue to be a significant market, particularly for lower grade coals, high sulphur coals, opportunity fuels and biomass. Successful operation of the SC unit at Lagisza is likely to lead to the further construction of such units in other countries, notably China.

As far as IGCC power generation is concerned, there are just six operational coal-based units in the world. However, a number of new projects are being developed, e.g. in Canada, China, the European Union, India and the United States; these are at different stages of planning and construction. For IGCC to be deployed more widely, immediate concerns such as cost and availability factors must be addressed. Concerted co-operation among technology vendors and utilities, and clarity in emission guidelines and incentives from governments are required if IGCC is to be deployed more widely. Technically, IGCC is well placed to embrace $\mathrm{CO}_{2}$ capture. The additional cost will be significant, but is generally expected to be lower than for PC systems.

Around $45 \%$ of the world's coal is either high-moisture or high-ash, resulting often in inefficient power plants using these coals. There is a strong need to develop less energy-intensive coaldrying technologies. While some efforts in coal drying are in progress in Australia, Germany and the United States, accelerating these efforts into large-scale integrated demonstrations is important. There is a similar need for the development of less energy- and water-intensive technology for coal beneficiation to reduce ash content. Success in developing more efficient coal-drying and beneficiation technologies will promote the wider use of the low-grade coals in either USC PC or IGCC applications.

Key R\&D needs for all these technologies have been identified as have the barriers to wider demonstration and successful deployment of technologies. The issue of CCS, which will impact significantly on both existing plants and plants to be built, is also discussed. At the current state of technology, $\mathrm{PC}$ or CFBC units retrofitted with $\mathrm{CO}_{2}$ capture will result in an efficiency penalty of up to 12 percentage-points. Based on the concept of what constitutes CCS ready, it can be seen that many existing PC plants may not be retrofitted with $\mathrm{CO}_{2}$ capture because they are too small or too inefficient. High efficiency is likely to be a main criterion for $\mathrm{CO}_{2}$ capture retrofit to any existing plant and, particularly if the uptake of CCS on a large-scale should be delayed, high efficiency plant will be an important means to reduce $\mathrm{CO}_{2}$ emissions.

Units retrofitted with $\mathrm{CO}_{2}$ capture will certainly experience some decreased efficiency, which would reduce overall capacity and result in lost exportable generation capacity. This may create a need for new capacity to offset the loss. Based on the information on new builds around the world, it appears that the majority are either SC or USC plants. It is conceivable that the majority of these plants would be suitable for $\mathrm{CO}_{2}$ capture retrofit. By 2030, it is estimated that up to $30 \%$ of the fleet would be retrofittable, while most of the remaining fleet may not be CCS-ready and would require assessment for either upgrading to high efficiency or complete replacement. The operability and flexibility of plants retrofitted for CCS needs to be assessed, in particular the dynamic performance during start-up, shut-down and changing load conditions. 
Oxy-fuel technology, which can in principle be used with both PC and CFBC units, is undergoing parallel development for $\mathrm{CO}_{2}$ capture. Vattenfall's PC-based pilot unit in Germany (30 MWth) entered commission in 2008 and is currently under test. A commercial scale of oxy-fuel combustion plant is planned, based on the testing results of the pilot plant. In 2010, the US DOE announced support to retrofit a $200 \mathrm{MWe}$ coal power plant in Illinois with advanced oxy-fuel combustion technology. In addition, a $30 \mathrm{MWe}$ PC unit in Australia is currently being retrofitted to demonstrate oxy-firing.

Regarding the choice of IGCC, PC and CFBC, an important issue is the method of selection for new power plants. While there are proposals for further demonstration of IGCC, SC and USC pulverised coal-fired power generation plants continue to form the majority of new plant orders. The possibility remains that PC plants may become so entrenched that IGCC, with or without CCS, may penetrate the market only when co-production of power and chemicals can be economically demonstrated (Topper et al., 2007).

\section{Key conclusions and the way forward}

Power plant construction and operation necessarily result from the world's continued and growing demand for energy. However, the technology deployed, the plant design and the operational strategy are all commercial decisions based on the economics of producing and supplying that energy to the end-user. This inevitably means that there will be a point at which higher efficiency and lower emissions come at a cost that cannot be justified. Where economic and regulatory conditions exist which shift this balance consistently in favour of higher efficiency and lower emissions, improvements become a commercial imperative and will become a normal part of operating a competitive business.

The development of supercritical steam cycles with progressively higher steam temperatures, combined with modern plant design and automation, provides significant potential for efficiency improvement and mitigation of $\mathrm{CO}_{2}$ emissions compared to existing coal-fired plant. These improvements will be realised through the progressive replacement of existing assets with reference to leading practice plant designs. The combined use of biomass in coal-fired plant could also achieve better biomass utilisation compared to smaller scale, relatively inefficient pure biomass boilers.

Though raising the efficiency and improving the performance of coal-fired power generation plant will provide substantial and important reductions in $\mathrm{CO}_{2}$ emissions over the next two decades and beyond, the greatest reduction in specific $\mathrm{CO}_{2}$ emissions from coal-fired plant will eventually be realised through the application of CCS technology. Consideration of the basic efficiency of the power plant will be a major factor in the economic viability of CCS. Potential exists for even greater $\mathrm{CO}_{2}$ reductions where $\mathrm{CCS}$ is applied to coal and biomass. 


\section{Abbreviations and Acronyms}

BFBC Bubbling fluidised bed combustion

BoA Lignite-fired power plant with optimised engineering (German abbreviation for Braunkohlenkraftwerk mit optimierter Anlagentechnik)

CCPI Clean Coal Power Initiative

CCS Carbon (or $\mathrm{CO}_{2}$ ) capture and storage

CSLF Carbon Sequestration Leadership Forum

CCSR CCS ready

CFBC Circulating fluidised bed combustion

CCTs Cleaner coal technologies

CO Carbon monoxide

$\mathrm{CO}_{2} \quad$ Carbon dioxide

DCS Distributed Control System

ENCAP Enhanced $\mathrm{CO}_{2}$ Capture Project

EC European Commission

FGD Flue gas desulphurisation

GHG Greenhouse gas

GRE Great River Energy

$\mathrm{H}_{2} \mathrm{O} \quad$ Water

$\mathrm{HHV} \quad$ Higher heating value

HP High pressure

IGCC Integrated gasification combined cycle

LCPD Large Combustion Plant Directive

LHV Lower heating value

LP Low Pressure

MTE Mechanical Thermal Expression

$\mathrm{NO}_{x} \quad$ Nitrogen oxides

$\mathrm{O}_{2} \quad$ Oxygen

O\&M Operation and Maintenance

PC Pulverised coal

R\&D Research and development

RD\&D Research, development and demonstration

SC Supercritical

SCR Selective catalytic reduction 
Power Generation from Coal

Ongoing Developments and Outlook

SNCR Selective non-catalytic reduction

$\mathrm{SO}_{2} \quad$ Sulphur dioxide

USC Ultra-supercritical

US DOE US Department of Energy

Page | 46

\section{Units of Measure}

kg Kilogramme

kJ Kilojoule

kW Kilowatt

kWh Kilowatt hours

$\mathrm{MPa} \quad$ Megapascal

MWth Megawatts thermal

MWe Megawatts electrical

GW Gigawatt

MJ Megajoule

Mt Million tonnes

t Tonnes

$\mu \mathrm{m} \quad$ Micrometre 


\section{References}

AGO (Australian Greenhouse Office) (2009), Integrating Consultancy - Efficiency Standards for Power Generation, Report No. HA00316.0, Sinclair Knight Merz Pty. Ltd., Canberra, Australia, www.environment.gov.au/settlements/ges/publications/skmreport.html.

Anand A., B. Mancuso, G. Wotzak and K. Collins (2006), "Coal IGCC Turbine Technology Improvements for Carbon-Free Fuels", presentation at $23^{\text {rd }}$ Annual Pittsburgh International Coal Conference, Pittsburgh, 25-28 September.

Beck, B. and J. Garrett (2010), Carbon Capture and Storage: Model Regulatory Framework, IEA Information Paper, OECD/IEA, Paris, November.

Beedie, M. and B. Brownlee (2008), Power's Wireless Future, Special Report, PowerTechnology.Com, 21 October, http://www.power-technology.com/features/feature44386.

Dalton, S. (2006), Ultrasupercritical Progress in the United States and in Coal Fleet for Tomorrow", 2nd Annual Conference of the Ultralsupercritical Thermal Power Technology Collaboration Network, 27-28 October, Qingdao, China.

Davidson R. and S. Santos (2010), Oxy-fuel Combustion of Pulverised Coal, Report CCC/168, IEA Clean Coal Centre, London, July, www.ieacoal.org.uk/publishor/system/component_view.asp?LogDocld=82355\&PhyDocID=7537.

Deshmukh S. (2008), Integrated Turbine Control Solution on Experion Platform, Honeywell Process Solutions, Pune, India, April, www.pennenergy.com/etc/medialib/platform7/pennenergy/whitepapers/category-pdfs.Par.20995.File.pdf.

Fernando R. (2008), Coal Gasification, CCC/140, IEA Clean Coal Centre, London, October.

Ferrer A. and Y. Kishinevsky (2008), "Green Strategies for Aging Coal Plants: Alternatives, Risks and Benefits", Power Engineering, Volume 112, Issue 7, Pub. PennWell, U.S., 1 July.

Ghosh S.R. (2007), "Global Coal Beneficiation Scenario and Economics of Using Washed Coal", workshop on Coal Beneficiation and Utilization of Rejects: Initiatives, Policies and Practice, Ranchi, India, 22-24 August.

Gierschner G. (2008), "COMTES700: On Track Towards the 50plus Power Plant", presentation at New Build Europe 2008, Düsseldorf, 4-5 March.

Global CCS Institute (2011), "The Global Status of CCS:2010", 8 March, http://www.globalccsinstitute.com/resources/publications/global-status-ccs-2010

Gollakota S.and C. Bullinger (2007), New Coal-Drying Technology Promises Higher Efficiency Plus Lower Costs and Emissions, Coal Power, Houston, July/August.

Goudappel E. and M. Berkhout (2006), "IGCC Based on Proven Technology Developing Towards 50\% Efficiency Mark", presentation at 7th European Gasification Conference, Barcelona, April.

Henderson C. (2008), Future Developments in IGCC, Report CCC/143, IEA Clean Coal Centre London, UK, December.

Huynh D., S. Huynh, H. Ellis, and M. McIntosh (2005), "Development of MTE Dewatering Technology for High Moisture Lignite at Pilot Scale", presentation at International Conference on Coal Science \& Technology, Okinawa, 9-14 October. 
IEA (International Energy Agency) (2007), Fossil Fuel-Fired Power Generation: Case Studies of Recently Constructed Coal- and Gas-Fired Power Plants, OECD/IEA, Paris.

IEA (2010a), World Energy Outlook 2010, OECD/IEA, Paris.

IEA (2010b), Energy Technology Perspectives 2010, OECD/IEA, Paris.

Page 48 IEA (2010c), Carbon Capture and Storage: Progress and Next Steps, IEA/CSLF Report to the Muskoka 2010 G8 Summit, OECD/IEA, Paris.

Innocenzi T. (2008), "Hazelwood 2030 Project", presentation at G8 Cleaner Fossil Fuels Workshop: What's Needed to Facilitate Upgrading or Replacement of Older Coal-fired Plants, IEA, Paris, France, 17-18 January, www.iea.org/work/workshopdetail.asp?WS ID=348.

Jantti T., H. Lampenius, M. Russkanen and R. Parkkonen (2009), "Supercritical OTU CFB Projects Lagisza $460 \mathrm{MW}_{\mathrm{e}}$ and Novocherkasskaya $330 \mathrm{MW}_{\mathrm{e}}$ ", presentation at Russia Power 2009, Moscow, 28-30 April.

Kather A., S. Rafailidis, C. Hermsdorf, M. Klostermann, A. Maschmann, K. Mieske, J. Oexmann, I. Pfaff, K. Rohloff, and J. Wilken (2008), Research and Development Needs for Clean Coal Deployment, Report CCC/130, IEA Clean Coal Centre, London, January.

Klutz H.-J., C. Moser and D. Block (2006), "WTA Fine Grain Drying - Module for Lignite-Fired Power Plants of the Future - Development and Operating Results of the Test Plant", VGB PowerTech International Journal, Vol. 11.

Kubek D., C. Higman, N. Holt, and R. Schoff (2007), " $\mathrm{CO}_{2}$ Capture Retrofit Issues”, presentation at Gasification Technologies 2007, San Francisco, 14-17 October, http://www.gasification.org/uploads/downloads/Conferences/2007/28KUBE.pdf

McIntosh M., and D. Huynh (2005), "Pre-drying of High Moisture Content Australian Brown Coal for Power Generation", presentation at International Coal Processing Exhibition and Conference, Lexington, Kentucky, 2-5 May.

Minchener A. (2010), Developments in China's Coal-fired Power Sector, Report CCC/163, IEA Clean Coal Centre, London, January.

Nalbandian H. (2004), Upgrading Instrumentation and Control in Coal-fired Plant, Report CCC/80, IEA Clean Coal Centre, London, January.

Nethercote N. (2008), "Mechanical Thermal Expression", presentation at China-Australia Dialogue on Clean Energy \& Environment, Beijing, 9 April.

NDRC (National Development and Reform Council) (2006), China's 11th Five-Year Plan, http://en.ndrc.gov.cn/hot/t20060529 71334.htm,.

Ren W. (2008), “Activities in Improving Coal-based Power Generation by China Guodian Corporation", presentation at IEA G8 Cleaner Fossil Fuels Workshop: What's Needed to Facilitate Upgrading or Replacement of Older Coal-fired Plants, Paris, 17-18 January, www.iea.org/work/workshopdetail.asp?WS ID=348.

Satyamurty M. (2007), "Coal Beneficiation Technology 2007: Initiatives, Policies and Practices", workshop on Coal Beneficiation and Utilization of Rejects: Initiatives, Policies and Practice, Ranchi, India, 22-24 August, http://fossil.energy.gov/international/International Partners/August 2007 CWG Meeting.ht $\underline{\mathrm{ml}}$. 
Schaarschmidt S., E. Jenikejew, G. Nitch and B. Michels (2005), "Performance Increase Through World Class Technology and Implementation", presentation at PowerGen Europe 2005, Milan, 28-30 June.

Sharma S. (2011), Private Communication to IEA, 13 July.

Smith I. (2009), Gas Turbine Technology for Syngas/Hydrogen in Coal-Based IGCC, Report CCC/155, IEA Clean Coal Centre, London, UK, October.

Sommerlad R. and K. Dugdale (2007), Dynamic Classifiers Improve Pulveriser Performance and More, Power, July.

St Baker, T. C. and L. A. Juniper (1982), Combustion Utilisation Assessment of Brown Coals and Lignites. Australian Coal Geology, p4 187.

Strauss, K., S. Berger, C. Bergins, F. Bielfeldt, R. Elsen and M. Erken (1999), “Mechanical/Thermal Dewatering of Brown Coal", VGB PowerTech International Journal, Vol. 2, pp. 44-49.

Topper J (2011), "Prospects for Coal Supply and Clean Coal Technologies Worldwide", Jülich, Germany, March, http://www2.fz-juelich.de/ief/ief-ste/datapool/steforum/ForumJuelich\%20meeting.pdf.

Topper J, A. Aumüller, C. Henderson, and H.-J. Meier (2007), “Clean Coal Technologies International Activities", VGB Powertech International Journal, Vol. 4, pp33-39.

US DOE (United States Department of Energy) (2008), Clean Coal Today, Spring 2008.

Utt, J. (2008), "Advanced CFB Developments and Activities by Foster Wheeler", presentation at IEA G8 Cleaner Fossil Fuels Workshop: What's needed to facilitate upgrading or replacement of older coal-fired plants, IEA, Paris, France, 17-18 January 2008, http://www.iea.org/work/workshopdetail.asp?WS ID=348.

Utt, J. (2011), Private Communication to IEA, 8 March 2011.

VGB, Electricity Generation, Figures \& Facts, 2010, http://www.vgb.org/en/data powergeneration.html.

Watanabe E., T. Nakano, K. Tanaka, M. Tsutsumi, Y. Tanaka, H. Ohyama, T. Miyawaki and T. Shinohara (2003), Development of High Efficiency Steam Turbine, Mitsubishi Heavy Industries, Technical Review, Vol. 40, No. 4, Tokyo. 





\section{iea}

\section{International Energy Agency}
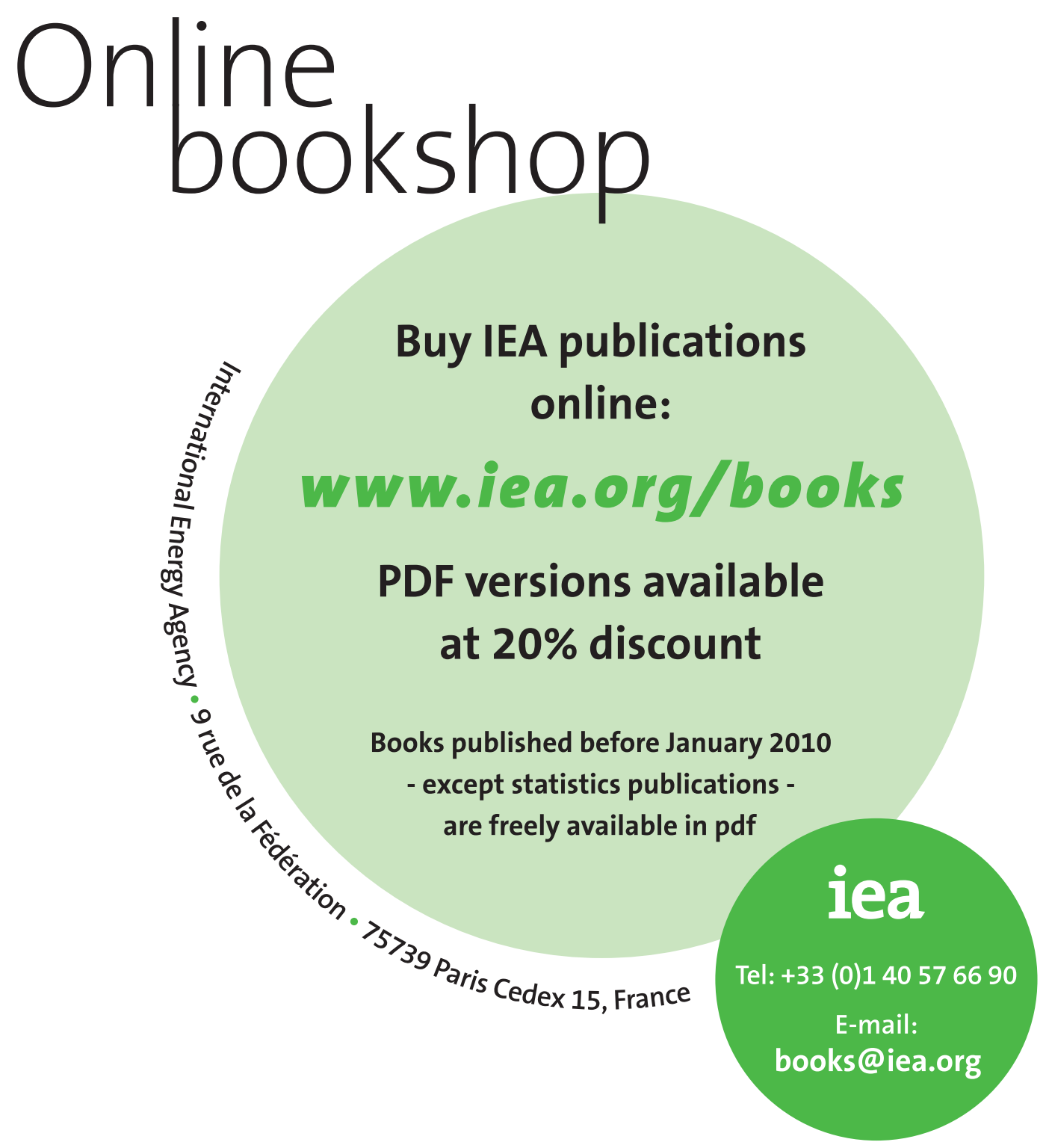
